\title{
Alexandre Petnys
}

\section{Avaliação quantitativa da compressão do tronco celíaco pelo ligamento arqueado mediano e da anatomia normal da origem do tronco celíaco em angiotomografias de pacientes assintomáticos}

Tese apresentada à Faculdade de Medicina da Universidade de São Paulo para obtenção do título de Doutor em Ciências

Programa de Fisiopatologia Experimental

Orientador: Prof. Dr. Antonio Eduardo Zerati

(Versão corrigida. Resolução CoPGr 6018/11, de 01 de novembro de 2011. A versão original está disponível na Biblioteca FMUSP) 
Aos meus pais, irmãos pelos exemplos de caráter; à minha esposa Cristina Helena Prado Kobata pelo incondicional apoio e nossos filhos Victor Kobata Petnys e Daniel Kobata Petnys, razões maiores de todas minhas ações. 


\section{AGRADECIMENTOS}

Ao Prof. Dr. Antonio Eduardo Zerati, Livre-Docente pela Disciplina de Cirurgia Vascular e Endovascular da Faculdade de Medicina da Universidade de São Paulo, meu orientador. Agradeço pela orientação, ensinamentos e paciência durante toda a elaboração deste projeto.

Ao Prof. Dr. Pedro Puech-Leão, Professor Titular da Disciplina de Cirurgia Vascular e Endovascular da Faculdade de Medicina da Universidade de São Paulo, pelas sempre incisivas sugestões, comentários e apoio.

Ao Prof. Dr. Nelson de Luccia, Professor Titular da Disciplina de Cirurgia Vascular e Endovascular da Faculdade de Medicina da Universidade de São Paulo, pelos ensinamentos, apoio e colaboração.

Aos Drs. Wellington Andraus, Glauco Fernandes Saes e Ana Cristina Aoun Tannuri, pelas críticas, sugestões, e aconselhamentos dispensados durante o exame de qualificação.

Aos residentes e preceptores do Serviço de Cirurgia Vascular e Endovascular do Hospital das Clínicas da Faculdade de Medicina da Universidade de São Paulo, e também aos residentes do Serviço de Cirurgia Vascular e Endovascular do Hospital do Servidor Público Municipal de São Paulo, razão de estímulo constante ao nosso aperfeiçoamento pessoal e profissional.

Aos Cirurgiões do Serviço de Cirurgia Vascular e Endovascular do Hospital das Clínicas da Faculdade de Medicina da Universidade de São Paulo: Prof. Dr. Erasmo Simão da Silva, Prof. Dr Ivan Benaduce Casella, pelo constante apoio e contribuição em minha formação. 
Esta tese está de acordo com as seguintes normas, em vigor no momento desta publicação:

Referências: adaptado de International Committee of Medical Journals Editors (Vancouver).

Universidade de São Paulo. Faculdade de Medicina. Serviço de Biblioteca e Documentação. Guia de apresentação de dissertações, teses e monografias.

Elaborado por Anneliese Carneiro da Cunha, Maria Julia de A. L. Freddi, Maria F. Crestana, Marinalva de Souza Aragão, Suely Campos Cardoso, Valéria Vilhena. $3^{a}$ ed. São Paulo: Divisão de Biblioteca e Documentações; 2011.

Abreviatura dos títulos dos periódicos de acordo com List of Journals Indexed in Index Medicus. 


\section{SUMÁRIO}

Lista de abreviaturas e siglas

Lista de figuras

Lista de tabelas

Lista de gráficos

Resumo

Abstract

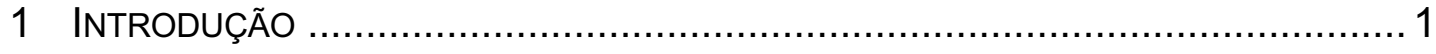

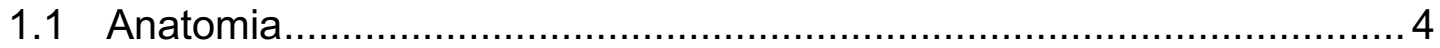

1.2 Estenose do Tronco Celíaco ...................................................... 8

1.3 Síndrome de Compressão do Tronco Celíaco pelo Ligamento

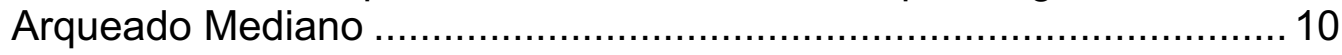

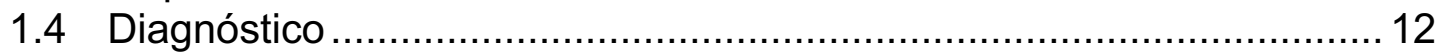

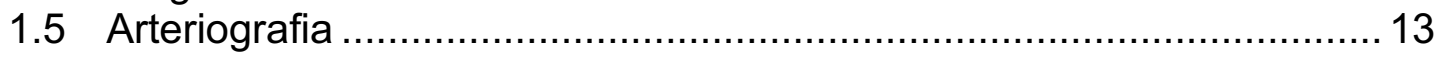

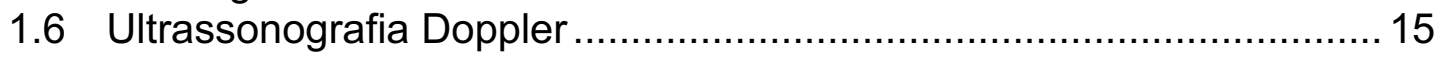

1.7 Tomografia Computadorizada/Angiotomografia .................................... 15

1.8 Ressonância Magnética/Angiorressonância.............................................. 17

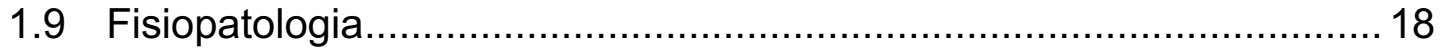

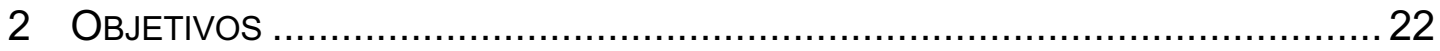

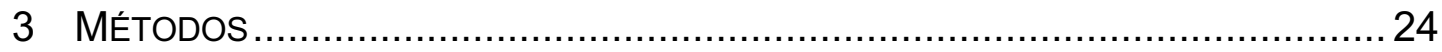

3.1 Análise Estatística ……………

4 RESULTADOS

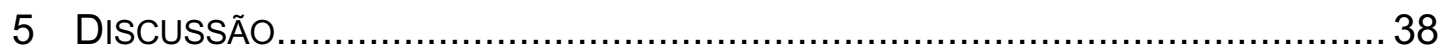

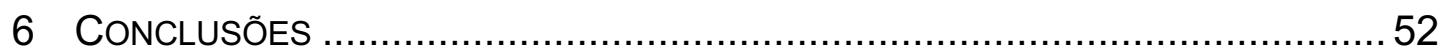

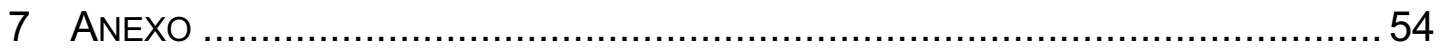

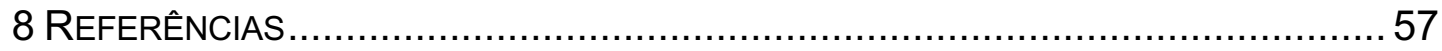

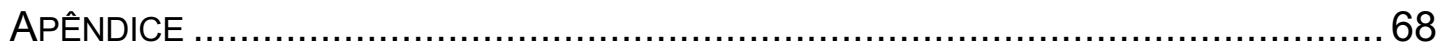




\section{LISTA DE ABREVIATURAS E SIGLAS}

\begin{tabular}{|c|c|}
\hline$A D$ & - Ângulo de dobra \\
\hline$A E$ & - Ângulo de emergência \\
\hline AMI & - Artéria mesentérica inferior \\
\hline AMS & - Artéria mesentérica superior \\
\hline AngioRM & - Angiorressonância \\
\hline AngioTC & - Angiotomografia computadorizada \\
\hline DICOM & - Digital Imaging and communications in medicine \\
\hline HCFMUSP & $\begin{array}{l}\text { - Hospital das Clínicas da Faculdade de Medicina da } \\
\text { Universidade de São Paulo }\end{array}$ \\
\hline IC 95\% & - Intervalo de confiança de $95 \%$. \\
\hline IMC & - Índice de massa corpórea \\
\hline L1 & - $1^{\text {a }}$ vértebra lombar \\
\hline L2 & - $2^{\mathrm{a}}$ vértebra lombar \\
\hline LAM & - Ligamento arqueado mediano \\
\hline $\mathrm{mmHg}$ & - Milímetros de mercúrio \\
\hline $\mathrm{p}$ & - p-valor \\
\hline PACS & - Picture Archiving and Communication System \\
\hline rho & - Coeficiente de correlação de Spearman \\
\hline T12 & - $12^{\mathrm{a}}$ vértebra torácica \\
\hline TC & - Tronco celíaco \\
\hline USP & - Universidade de São Paulo \\
\hline VPS & - Velocidade de pico sistólico \\
\hline
\end{tabular}




\section{LISTA DE FIGURAS}

Figura 1 - Representação esquemática dos níveis vertebrais da origem do tronco celíaco e ligamento arqueado mediano

Figura 2 - Representação gráfica da anatomia local do tronco celíaco, ligamento arqueado mediano e estruturas adjacentes.

Figura 3 - Mensuração do ângulo de emergência................................. 27

Figura 4 - Mensuração do ângulo de dobra ....................................... 28

Figura 5 - Estenose do tronco celíaco com aspecto em gancho .............. 34

Figura 6 - Estenose crítica/suboclusão do tronco celíaco ........................ 35

Figura 7 - Estenose crítica do tronco celíaco, ausência de aspecto em gancho

Figura 8 - Suboclusão do TC, LAM projetando-se sobre sua origem .........36

Figura 9 - Trajeto habitual do tronco celíaco ..................................... 43

Figura 10 - Aspecto em "gancho" sem estenose associada .....................46 


\section{LISTA DE TABELAS}

Tabela 1 - Dados antropométricos dos 321 doadores de acordo

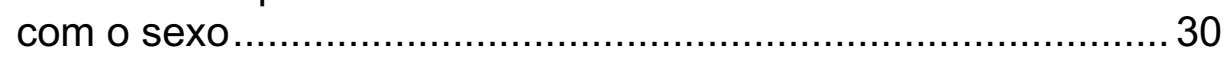

Tabela 2 - Valores dos ângulos de dobra e emergência em doadores homens e mulheres.................................................. 31

Tabela 3 - Correlação de Spearman entre os ângulos aferidos e parâmetros clínicos

Tabela 4 - Características anatômicas e dados demográficos dos doadores com estenose do tronco celíaco $>50 \%$ 


\section{LISTA DE GRÁFICOS}

Gráfico 1 - Correlação entre os dados antropométricos de IMC e ângulos aferidos em homens e mulheres ................................. 32

Gráfico 2 - Distribuição das alturas de origem do tronco celíaco (vermelho) e margem inferior do ligamento arqueado mediano (azul), em relação às vértebras. 33 


\section{RESUMO}

Petnys A. Avaliação quantitativa da compressão do tronco celíaco pelo ligamento arqueado mediano e da anatomia normal da origem do tronco celíaco em angiotomografias de pacientes assintomáticos [tese]. São Paulo: Faculdade de Medicina, Universidade de São Paulo; 2021.

Introdução: o uso crescente de angiotomografias computadorizadas tem resultado em diagnósticos mais frequentes de compressão do tronco celíaco pelo ligamento arqueado mediano. Os sinais de compressão têm sido descritos como estenose do vaso e aspecto em gancho ou $\mathrm{J}$ nas reconstruções sagitais. A importância do sinal do gancho, no entanto, não foi documentada em estudos da anatomia normal do tronco celíaco. Métodos: foram revistas angiotomografias de 344 doadores renais assintomáticos, sem história de dor abdominal ou perda ponderal mensurando-se o ângulo de emergência do tronco celíaco em relação à aorta e o ângulo de dobra em direção cranial ou caudal do tronco antes da sua primeira ramificação. Os valores dos ângulos foram correlacionados com medidas antropométricas dos indivíduos como peso, altura e índice de massa corpórea. A ocorrência de estenose $>50 \%$ na porção proximal do tronco celíaco, atribuída à compressão pelo ligamento arqueado mediano foi determinada na amostra. Resultados: as medidas dos ângulos foram obtidas em 321 indivíduos. O tronco celíaco apresentou emergência da aorta em ângulo < 90 graus em todos os pacientes (variação 7-83 graus), e < 45 graus em 292 (90\%). O ângulo de dobra variou de 66 a 208 graus. Antes de sua primeira ramificação o tronco celíaco apresentou desvio cranial em 306 (95\%) dos pacientes, permaneceu sem desvio em somente um dos casos e apresentou desvio caudal em $14(4 \%)$. O ângulo de emergência apresentou correlação positiva com o peso corporal nas mulheres. O ângulo de dobra apresentou correlação negativa com o peso corporal em homens e mulheres. $O$ índice de massa corpórea apresentou correlação positiva com o ângulo de emergência e correlação negativa com ângulo de dobra em ambos os sexos. Estenose $>50 \%$ da porção proximal do tronco celíaco foi encontrada em 11 casos $(3,4 \%)$. Em somente 2 destes foi observada uma angulação cranial muito acentuada do tronco celíaco, o que poderia ser interpretado como formato ou sinal de gancho ou $\mathrm{J}$. Conclusões: a anatomia normal do tronco celíaco, analisada em imagens de angiotomografia, mostra frequentemente trajeto inicial caudal seguido de inclinação cranial não acentuada. Compressão do tronco celíaco pelo ligamento arqueado mediano é rara e o sinal descrito como gancho é pouco frequente nesses pacientes com compressão. $O$ aspecto 
assemelhando-se a um gancho ou formato em $J$ não deve ser interpretado, portanto, como resultante de compressão extrínseca.

Descritores: Anatomia; Artéria celíaca; Doenças vasculares; Arteriopatia oclusivas; Síndrome do ligamento arqueado mediano; Diagnóstico por imagem; Angiografia por tomografia computadorizada. 


\begin{abstract}
Petnys A. Quantitative avaliation of celiac artery compression by the median arcuate ligament and normal anatomy of celiac origin on computed tomography angiographies in asymptomatic patients [thesis]. São Paulo: "Faculdade de Medicina, Universidade de São Paulo"; 2021.
\end{abstract}

Introduction: the increasing use of computed tomography (CT) angiography has led to more frequent diagnoses of celiac artery compression (CAC) by the median arcuate ligament (MAL). The signs of CAC by the MAL have been described as stenosis and a hook or $\mathrm{J}$ appearance on sagittal views. The importance of the "hook signal," however, has not been documented by studies of the normal anatomy of the celiac axis. Methods: CT angiography images of 344 completely asymptomatic, live kidney donors (without history of chronic abdominal pain or weight loss) were reviewed. The angle of emergence $(A E)$ of the celiac axis from the aorta and the angle of upward or downward shifting of the celiac axis before its first branch (fold angle [FA]) were measured. Weight, height, and body mass index were obtained from our electronic database, and correlations with the angles measured were tested. The occurrence of stenosis $>50 \%$ at the origins of the celiac axis was also determined in the sample. Results: measurements were possible in 321 cases. The celiac axis was found to leave the aorta at an angle of $<90$ degrees in all patients (AE range, 7-83 degrees) and $<45$ degrees in 292 $(90 \%)$ patients. The FA ranged from 66 to 208 degrees. Before the first branch, the celiac trunk shifted upward in 306 (95\%) patients, remained straight in just one of them, and shifted downward in $14(4 \%)$. The AE was positively correlated with weight in women. The FA was negatively correlated with weight in men and women. Body mass index was positively correlated with $\mathrm{AE}$ and negatively correlated with $\mathrm{FA}$ in both men and women. In 11 cases $(3.4 \%)$, stenosis $>50 \%$ was found at the origin of the celiac axis. In only two patients, the celiac axis had an upward slope after the stenosis, which could be interpreted as a hook shape. Conclusions: the normal anatomy of the celiac axis, when seen on CT angiography images, demonstrates that it exits the aorta downward and then shifts upward. CAC by the MAL occurs in $3.42 \%$ of the normal asymptomatic population; a hook or $\mathrm{J}$ shape is not visible in most cases in that subgroup. The hook or $\mathrm{J}$ shape should not be interpreted as resulting from external compression.

Descriptors: Anatomy; Celiac artery; Vascular diseases; Arterial oclusive diseases; Median arcuate ligament syndrome; Diagnostic imaging; Computed tomography arteriography. 
1 INTRODUÇÃo 
A compressão do tronco celíaco (TC) pelo ligamento arqueado mediano (LAM) como entidade sintomática foi inicialmente descrita por Harjola ${ }^{1}$, em 1963, ao relatar paciente com dor abdominal pós-prandial associada à presença de sopro em região epigástrica, com melhora dos sintomas após secção de tecido fibrótico envolvendo o tronco celíaco. Do ponto de vista anatômico, Lipschutz², em 1917, em estudo cadavérico das variações anatômicas das ramificações do tronco celíaco, observou que não raramente o mesmo era coberto parcialmente pelo diafragma, com hipoplasia do tronco e de seus ramos, descrevendo provável deficiência do suprimento sanguíneo.

Séries de casos relatados por Dunbar et al. ${ }^{3}$, Marable et al. ${ }^{4}$, Molnar et al. ${ }^{5}$ e Harjola e Lahtiharju ${ }^{6}$, sugeriram a existência de síndrome clínica associada à presença de compressão do tronco, com sintomas mais frequentes de dor pós-prandial habitualmente em região epigástrica, associada a vômitos, perda ponderal e presença de sopro sistólico epigástrico. Achados arteriográficos da compressão do tronco celíaco, sobretudo em aquisições em projeção lateral, foram descritos como típicos, com estenose de sua porção proximal e deslocamento inferior do tronco celíaco em direção à aorta, seguida de inclinação cranial, assemelhando-se ao formato de $\mathrm{U}$, ou $\mathrm{J}$, ou também denominado aspecto em gancho, ou sinal 
do gancho ${ }^{3-5}$. Em frequência variável, podem ser também observados aumento de colaterais na arcada pancreatoduodenal, e presença de dilatação pós-estenótica. A associação de sinais radiológicos e sintomas do trato gastrointestinal, e ausência de outras causas que justificassem as queixas, parecia indicar a necessidade de descompressão cirúrgica do tronco celíaco.

Entretanto, estudos arteriográficos mostram a presença destes mesmos sinais e aspecto em pacientes assintomáticos ou com queixas abdominais distintas em proporção variável, recomendando-se cautela no diagnóstico de síndrome associada à compressão do tronco celíaco ${ }^{7}$. A ausência de uma explicação plenamente satisfatória para a fisiopatologia dos sintomas e resultados variáveis na melhora dos mesmos após a liberação do tronco, com presença de recorrências, levou alguns autores a questionarem a existência da síndrome ${ }^{8}$.

Atualmente o diagnóstico de doença oclusiva dos vasos viscerais tem sido realizado por meio de estudo tomográfico, em substituição à aorto/arteriografia convencional, em virtude da menor invasibilidade e informações adicionais fornecidas pela tomografia ${ }^{9,10}$. O desenvolvimento e maior acessibilidade de equipamentos de tomografia, têm proporcionado um número crescente de exames. Achados incidentais tomográficos são descritos com maior frequência, motivando sociedades de radiologia a estabelecerem recomendações diante dos mesmos ${ }^{11}$. O diagnóstico radiológico de compressão do tronco celíaco pelo ligamento arqueado tem sido relatado com frequência variável em pacientes submetidos à tomografia 
na investigação de queixas abdominais, ou outras condições não relacionadas, e até mesmo em indivíduos assintomáticos. No entanto, a importância de sinais de compressão e sua relação com a anatomia normal do tronco celíaco em estudos tomográficos é desconhecida, havendo poucas descrições do comportamento anatômico habitual do TC em sua porção inicial, nos motivando à realização do presente estudo.

\subsection{Anatomia}

O tronco celíaco é o primeiro ramo visceral da aorta abdominal, apresentando origem mais frequentemente entre espaço intervertebral de T12/L1 e 1/3 superior de L1, com variações de T11 até mais distais em L2 ${ }^{12,13}$. As variações de altura são explicadas pela sua migração caudal durante o desenvolvimento embrionário ${ }^{14}$. A maior parte dos estudos anatômicos sobre o tronco celíaco é direcionada à observação e relato de frequência e padrões de suas ramificações, classicamente descritas ${ }^{15,16}$, porém pouco se relata sobre seu trajeto inicial em si. Por meio de seus principais ramos (artéria esplênica, artéria gástrica esquerda e artéria hepática comum), é responsável pelo suprimento sanguíneo do estômago, baço, pâncreas, fígado e porção proximal do duodeno. Existe ampla rede de colaterais comunicando o território do tronco celíaco com ramos da artéria mesentérica superior (AMS), principalmente pelas artérias pancreaticoduodenais, ou arcada pancreaticoduodenal, e artéria pancreática dorsal. O tronco celíaco apresenta comprimento variável, de $8 \mathrm{~mm}$ a $26 \mathrm{~mm}$ até sua primeira ramificação ${ }^{17}$, podendo sofrer compressão extrínseca pelo 
ligamento arqueado mediano, muitas vezes intimamente relacionado neste segmento proximal. A sua origem pode ser parcial ou totalmente coberta pelo ligamento arqueado mediano ${ }^{18}$, sendo observado, em estudo realizado em Tel Aviv com 46 cadáveres, tronco celíaco coberto pelo ligamento arqueado mediano em $89 \%$ ( $37 \%$ total e $52 \%$ parcialmente), concluindo os autores que a compressão do tronco celíaco é uma situação anatômica normal e comum ${ }^{19}$ (Figura 1).

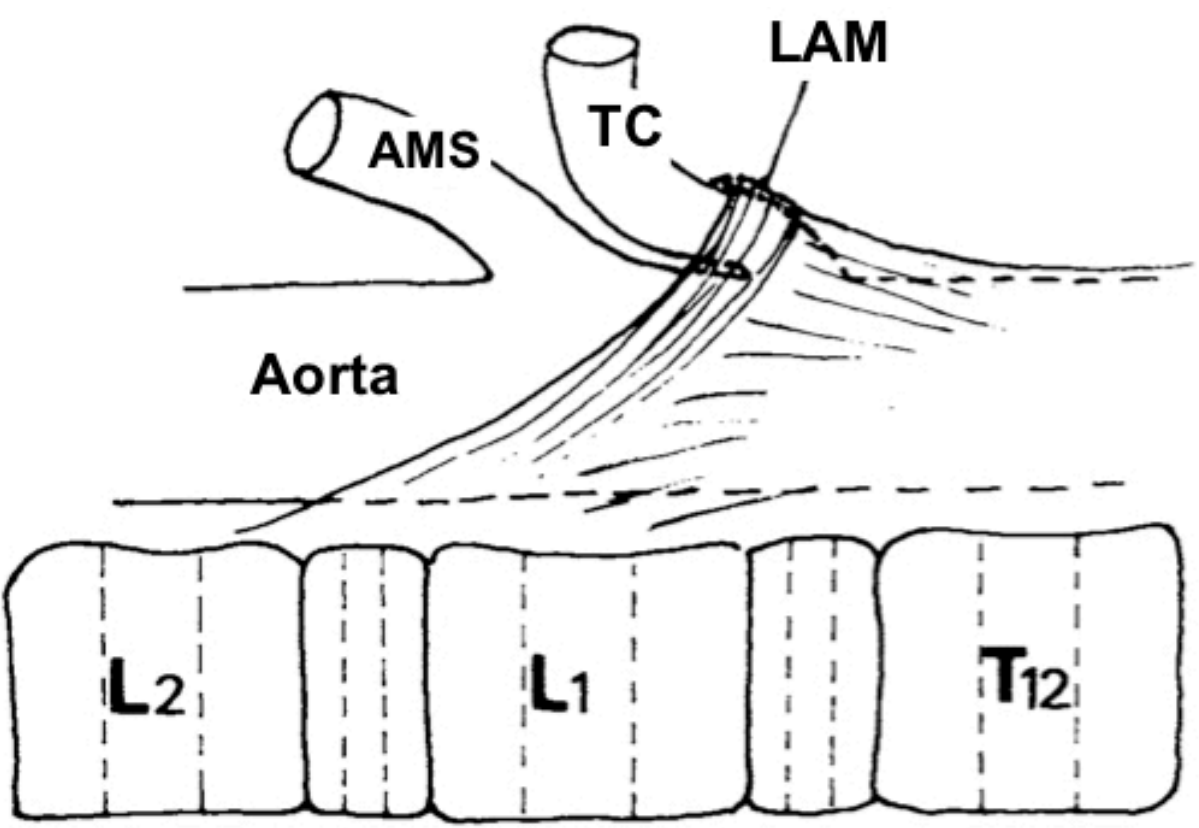

A imagem ilustra a cobertura da origem do tronco celíaco pelo ligamento arqueado mediano.

AMS: artéria mesentérica superior; TC: tronco celíaco; LAM: ligamento arqueado mediano; T12: $12^{\mathrm{a}}$ vértebra torácica; L1: $1^{\mathrm{a}}$ vértebra lombar, L2: $2^{\mathrm{a}}$ vértebra lombar.

Figura 1 - Representação esquemática dos níveis vertebrais da origem do tronco celíaco e ligamento arqueado mediano. Vista lateral. [Fonte: Paz et al. ${ }^{19}$ ]

Lindner e Kemprud ${ }^{18}$ relatam a origem do TC no nível ou acima da borda inferior do LAM em 33\%, e pelo menos parte do orifício acima do LAM em $48 \%$ de 75 cadáveres. Estudando a relação entre TC e LAM e sua posição relativa aos corpos vertebrais, concluíram que TC acima do LAM é resultado 
de um ligamento anormalmente baixo e não por um tronco excessivamente alto em sua origem. Observaram ainda que, com a progressão da idade, devido à frouxidão e ptose dos tecidos, a relação do TC/LAM com os níveis vertebrais se torna mais baixa. Outros achados foram que o ângulo entre o TC e Aorta parece diminuir com a idade, com achado de ângulos menores que 30 graus, que apresentam aumento para mais de 50 quando realizada a liberação do LAM. Outro estudo de 99 cadáveres relata a inexistência de distância mensurável entre o TC e LAM em 92,6\% dos casos, com 33,7\% mostrando evidência de compressão ou kinking do $\mathrm{TC}^{20}$.

O ligamento arqueado mediano é constituído por banda fibro-tendínea que conecta os pilares diafragmáticos direito e esquerdo, constituindo a margem anterior do hiato aórtico, por onde passam a aorta, ducto torácico e veia ázigos. Os pilares diafragmáticos têm origem na porção anterior dos corpos vertebrais de L1 a L4 a direita e de L1-L2/L1-L3 a esquerda, ascendendo lateral e superiormente até o hiato aórtico, conectando-se pelo LAM, que cruza anteriormente a aorta habitualmente ao nível da primeira vértebra lombar $(\mathrm{L} 1)^{21}$. Em seu trajeto anterior à aorta, pode cobrir parcial ou totalmente a origem do tronco celíaco, provocando uma curvatura caudal do mesmo proximalmente, aproximando-o da parede anterior da aorta; e indentação em seu aspecto superior, seguida de um trajeto ascendente. Alguns autores sustentam que um nível anormalmente baixo do LAM ou origem do TC mais alta provocariam a compressão. É discutido, ainda, se as artérias frênicas, quando apresentam origem abaixo do ligamento, com o TC situado posterior ao mesmo, exerceriam o efeito de tracionar o TC contra o 
LAM, provocando a compressão ${ }^{18}$. O LAM apresenta tamanho e forma variável, podendo formar um cordão fibroso bem definido de espessura variando de $1 \mathrm{~mm}-3 \mathrm{~mm}$ até uma massa amorfa. Sua altura em relação aos corpos vertebrais também é variável, de T11 até L2, mais frequentemente entre T12-L1. Relacionado intimamente ao LAM encontra-se complexo ganglionar do plexo celíaco, que flanqueia lateralmente a aorta e a origem do tronco celíaco (Figura 2). As fibras ganglionares se interconectam livremente ao redor do tronco celíaco, formando por vezes um infiltrado de tecido conectivo/fibroso e gorduroso junto ao LAM ${ }^{21,22}$.

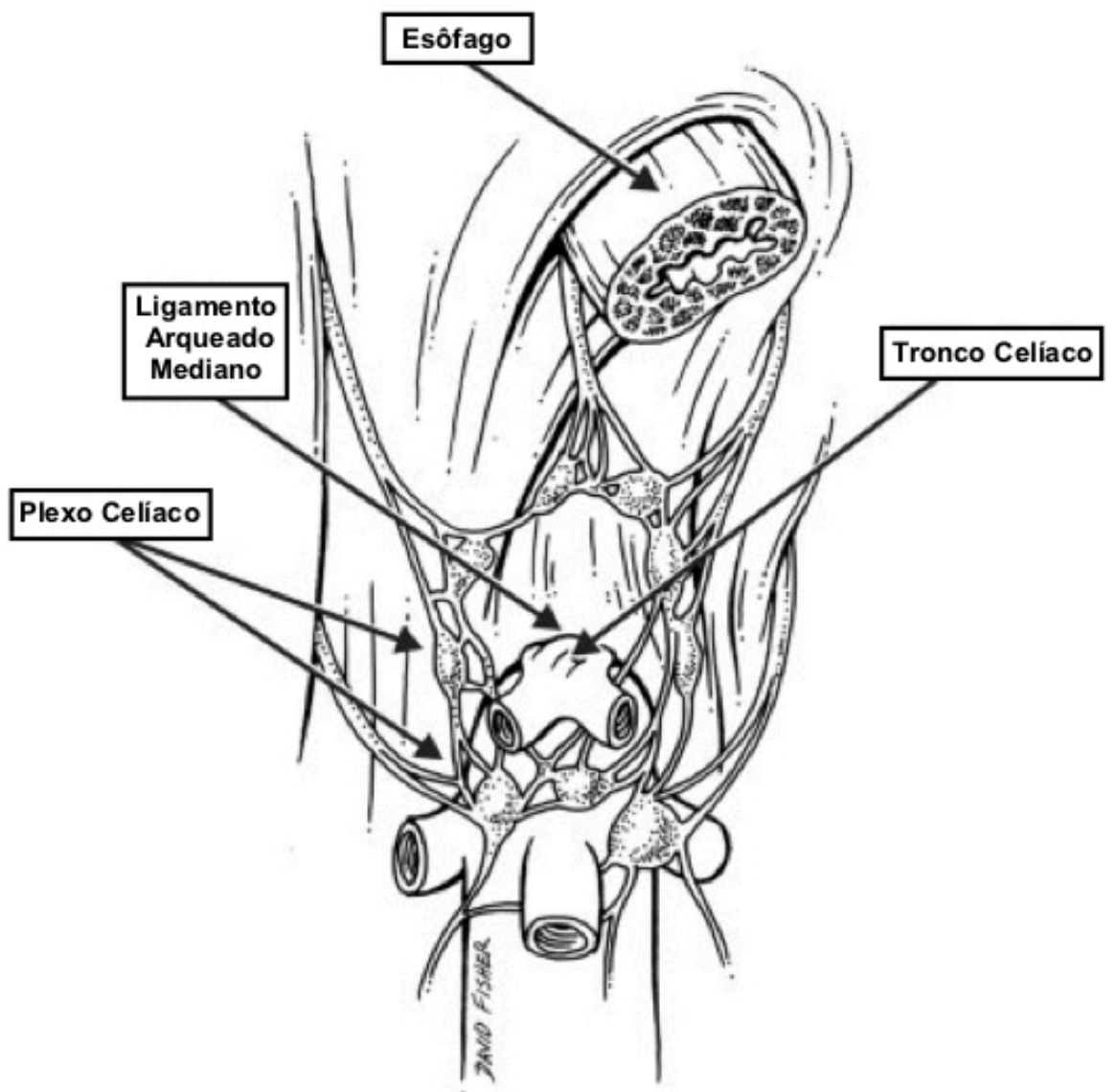

Figura 2 - Representação gráfica da anatomia local do tronco celíaco, ligamento arqueado mediano e estruturas adjacentes [Fonte: Loukas et al. ${ }^{22}$ ] 


\subsection{Estenose do Tronco Celíaco}

As estenoses/oclusões do tronco celíaco podem ser secundárias a aterosclerose, compressão extrínseca pelo ligamento arqueado mediano, compressão/invasão tumoral, vasculites, fibrodisplasia, fibrose retroperitoneal ${ }^{23}$.

Em estudo arteriográfico de 713 pacientes, Bron e Redman ${ }^{24}$ relataram a presença de estenose ou oclusão de um ou mais vasos viscerais (TC, AMS, AMI) em 17,3\%; com lesões em tronco celíaco sendo as mais frequentes (12,5\% dos casos). O TC também é o vaso que apresenta maior frequência de lesões isoladas. As estenoses de vasos viscerais apresentam incidência decrescente conforme se caminha do TC em direção à artéria mesentérica inferior (AMI); o contrário ocorrendo em lesões oclusivas. Lesões em tronco celíaco parecem se iniciar mais precocemente, com incidência maior em faixas etárias mais jovens, se comparadas a lesões isoladas de outros vasos. A distribuição destas lesões de TC entre os sexos é igual, porém com ligeira predominância para o sexo feminino em indivíduos abaixo dos 50 anos. Os autores ainda identificaram dois tipos de estenoses: concêntricas, associadas à doença aterosclerótica da aorta, e excêntricas, com assimetrias superiores ou inferiores. No tronco celíaco as lesões se apresentam dos dois tipos, porém, quando associadas a lesões dos outros vasos viscerais, apresentamse de forma concêntrica em praticamente sua totalidade, o que parece confirmar a sua etiologia aterosclerótica.

Levin e Baltaxe $^{7}$ relataram a prevalência de $24 \%$ de estenoses maiores que $50 \%$ em indivíduos assintomáticos, relatando aspecto em $U$ da porção proximal do TC com compressão na porção superior do mesmo, em aortografia com projeção lateral. 
Colapinto et al. ${ }^{25}$, analisando 152 aortografias em projeção lateral identificaram quatro tipos morfológicos de estenoses do TC. O tipo I apresenta-se como lesão assimétrica na porção superior e proximal da artéria, com óstio preservado e deslocamento inferior da artéria contra a aorta/AMS; sendo o padrão mais observado nos casos de compressão extrínseca. O tipo II é predominantemente ostial, associado à aterosclerose da aorta. Tipo III com estenose simétrica, nos primeiros centímetros da artéria, podendo ser associado a aterosclerose ou acometimento/invasão tumoral. O Tipo IV é semelhante ao III, porém com aspecto irregular da parede, associado a aterosclerose. Os autores encontraram estenose do tronco celíaco em 49\% dos pacientes submetidos à angiografia abdominal com indicações variadas, sendo o tipo I o mais frequente, totalizando $63 \%$ das estenoses do TC; com estenoses maiores que $50 \%$ da luz em $68 \%$ dos casos desse subtipo. O tipo I ocorreu em todas as idades; e observado com maior frequência os demais tipos, associados a aterosclerose, em faixas etárias maiores. Adicionalmente, o tipo I não foi relacionado a um nível anormalmente alto da origem do TC.

Estenoses ou oclusões do tronco celíaco, geralmente são bem toleradas quando não reconhecidas previamente, porém podem determinar isquemia hepática ou gástrica em procedimentos como gastroduodenopancreatectomias ${ }^{26}$, em virtude da ligadura de colaterais da arcada pancreaticoduodenal; assim como trombose de artéria hepática após transplante hepático, com isquemia do enxerto e das vias biliares ${ }^{27}$. Estenoses do TC comprometem ou impossibilitam o acesso vascular em procedimentos diagnósticos sobre o fígado, como embolizações ou quimioembolizações $^{28 ;}$ e estão associadas ao desenvolvimento de 
aneurismas viscerais da arcada pancreaticoduodenal, possivelmente por aumento de fluxo por essas vias colaterais comunicando território da AMS com território do TC 29,30 . Portanto, mesmo assintomáticas, a identificação destas lesões pode ter importância clínica.

\subsection{Síndrome de Compressão do Tronco Celíaco pelo Ligamento}

\section{Arqueado Mediano}

Lipschutz² em 1917, em estudo cadavérico das variações anatômicas das ramificações do tronco celíaco, observou que não raramente o mesmo era coberto parcialmente pelo diafragma, levando a deficiência do suprimento sanguíneo. Embora este fenômeno de cobertura parcial ou total da origem do tronco celíaco pelo ligamento arqueado mediano levando à compressão do mesmo já houvesse sido observado, o primeiro relato de sintomatologia associada a essa condição anatômica data de 1963, com Harjola ${ }^{1}$ descrevendo paciente do sexo masculino com queixa de dor abdominal pósprandial e presença de sopro sistólico em região epigástrica submetido a laparotomia exploradora, tendo como o único achado de nota, frêmito em tronco celíaco, sendo proposta a endarterectomia do mesmo. Na dissecção observou-se envolvimento do tronco celíaco em sua porção proximal por denso tecido cicatricial e atribuído ao gânglio celíaco, procedendo-se à secção do mesmo, com inesperada liberação do tronco até sua origem e notando-se uma depressão provocada pela fibrose na parede arterial, semelhante a uma ligadura. A artéria não apresentava evidência de doença aterosclerótica, com cessação do frêmito após liberação da mesma. O paciente evoluiu no pósoperatório com resolução da sintomatologia. 
Posterior ao relato de Harjola ${ }^{1}$, Marable et al. ${ }^{5}$, em 1966 relataram três casos adicionais de mulheres jovens com achado de compressão extrínseca do TC, associada a sopro epigástrico sistólico e sintomas de dor abdominal pós-prandial, habitualmente em cólica, com algum alívio ao assumir posição genupeitoral. Náuseas, vômitos e diarreia também foram descritos, mas sem um padrão característico.

Em 1965, Dunbar et al. ${ }^{3}$ relataram série de 15 pacientes com sintomas vagos e intermitentes de dor abdominal pós-prandial, associada a diarreia, náuseas, vômitos, perda ponderal e sopro epigástrico. Os pacientes eram jovens, em sua maioria mulheres, com exames laboratoriais e radiografias abdominais sem alterações significativas. À aortografia em projeção lateral evidenciavam deslocamento inferior do TC em direção à aorta e estenose de sua porção proximal. Treze dos pacientes foram submetidos à descompressão do TC, com alívio dos sintomas. Em virtude desta publicação alguns autores passaram a denominar a sintomatologia associada à compressão extrínseca do TC como síndrome de Dunbar. Em outra publicação, Harjola e Lahtiharju ${ }^{6}$ relataram outros 13 casos, empregando o termo "síndrome do tronco celíaco", e descreveu três tipos de estenose: constricção pelo gânglio celíaco; constricção pela margem distal do hiato aórtico (LAM) distal ao ponto de origem do TC, e compressão mista. Atribuiu a etiologia à desproporção anatômica entre o TC e LAM e à proliferação fibrótica do gânglio/plexo celíaco ${ }^{6}$. Marable et al. ${ }^{4}$, atualizando a experiência prévia, relataram a presença da síndrome em 30 pacientes, todos com a presença de sopro epigástrico, dor pós-prandial e náuseas, 
vômitos e diarreia de apresentação variável; atribuindo a compressão pela porção anterior do hiato aórtico (LAM), à altura de origem do TC anormalmente alta em relação ao mesmo.

\subsection{Diagnóstico}

Classicamente, a partir dos primeiros relatos da síndrome de compressão do TC, identificou-se a tríade de dor abdominal pós-prandial, presença de sopro epigástrico e sinais arteriográficos em aortografias realizadas em projeção lateral. Eventualmente a dor pode ser aliviada ao se assumir a posição genupeitoral, por relaxamento dos tecidos e da compressão. A dor pode ser mal definida, intermitente e vaga, assemelhando-se a quadros dispépticos ou funcionais ${ }^{31}$.

O sopro habitualmente é relatado em região epigástrica, sistólico, com acentuação do mesmo durante a expiração. Reuter ${ }^{32}$ demonstrou em aortografias laterais a acentuação da compressão do tronco durante movimentos de expiração, variando da ocorrência de depressão no aspecto superior da artéria até de oclusão da mesma, associada a ocorrência ou acentuação do sopro. A presença de sopro epigástrico em indivíduos assintomáticos tem sido relatada em $6,5 \%$ a $16 \%{ }^{33,34}$. Em análise de 503 pacientes submetidos à angiografia abdominal, McLoughlin et al. ${ }^{35}$ relataram a ocorrência de sopros abdominais em $21 \%$, a grande maioria em região epigástrica, atribuindo a maior parte deles à ocorrência de estenose do tronco celíaco. Estenose ou oclusão de TC foram encontradas em $38 \%$ desta série, $58 \%$ dos quais atribuídas à compressão extrínseca do mesmo. 
Exames radiográficos convencionais e laboratoriais apresentam-se habitualmente normais, e exames complementares como endoscopia, estudos funcionais do trato gastrointestinal, ultrassonografia e tomografia computadorizada são realizados para excluir outras patologias que justifiquem os sintomas, antes de se proceder ao diagnóstico de síndrome de compressão. Atualmente o diagnóstico de síndrome de compressão do tronco celíaco pelo ligamento arqueado mediano envolve a correlação dos dados clínicos com achados radiológicos; e exclusão de outras doenças que justifiquem os sintomas.

\subsection{Arteriografia}

A arteriografia tem relevância histórica desde os primeiros relatos da compressão do tronco celíaco pelo ligamento arqueado mediano, com a estenose da porção proximal do tronco celíaco e aspecto em gancho do mesmo considerados como típicos da síndrome. A incidência de achado de lesões em tronco celíaco, com estenoses $>50 \%$ da luz em estudos arteriográficos varia de $1 \%$ a $28 \%{ }^{24,25,36,37}$. Essa grande variabilidade pode ser explicada pelas diferentes indicações de realização dos exames e pelos protocolos diversos de realização dos mesmos. Maiores incidências foram encontradas em pacientes submetidos à aortografia em projeção lateral, que habitualmente não constava em protocolos de angiografia abdominal no passado. A projeção lateral em alguns protocolos só era realizada eventualmente na presença de circulação colateral da arcada pancreatoduodenal, nas projeções anteroposteriores, sugerindo a ocorrência de lesões no tronco celíaco. Levin e Baltaxe $^{7}$ relatando a 
incidência de $24 \%$ de estenoses do tronco celíaco em pacientes assintomáticos submetidos à aortografia em projeção lateral, comentam que a maior parte destes casos não demonstravam colaterais evidentes na projeção frontal, podendo ser subnotificados se realizada somente esta projeção.

Os achados de compressão são comumente descritos como deslocamento inferior da porção proximal do TC celíaco em direção à aorta, diminuindo a distância do mesmo em relação à AMS; presença de incisura ou depressão no aspecto superior do TC proximal, provocando estenose assimétrica ou excêntrica; aspecto em $U$ ou $\mathrm{J}$, também denominado sinal do gancho; desenvolvimento de circulação colateral entre TC e AMS, principalmente da arcada pancreaticoduodenal; presença de dilatação pós-estenótica; e padrão de fluxo mostrando enchimento retrógrado dos ramos do TC via colaterais pancreaticoduodenais ao se realizar cateterização seletiva da $\mathrm{AMS}^{3,25,31,38,39}$. O aspecto em gancho do tronco celíaco pode ser interpretado como o seu deslocamento em direção à aorta em sua porção inicial, provocado pelo LAM, seguido por acentuada inclinação cranial, reassumindo seu trajeto até sua primeira ramificação.

Entretanto, estudos arteriográficos mostram a presença destes mesmos sinais e aspecto em pacientes assintomáticos ou com queixas abdominais distintas em proporção variável, recomendando-se cautela no diagnóstico de síndrome associada à compressão do tronco celíaco ${ }^{7}$. 


\subsection{Ultrassonografia Doppler}

O ultrassom com estudo Doppler pode ser realizado para identificação de estenoses do tronco celíaco. Trata-se de exame não invasivo que permite a avaliação dinâmica do fluxo em artérias com estenose ${ }^{40}$, embora operador dependente e sujeito a dificuldades de visualização dos vasos em pacientes com preparo inadequado ou obesos. A presença de velocidade de pico sistólico (VPS) $>200 \mathrm{~cm} / \mathrm{s}$ ou ausência de fluxo em tronco celíaco parece indicar estenose $>70 \%$ deste vaso com sensibilidade e especificidade $>80 \% 41$.

A realização da medida da VPS durante os movimentos respiratórios, observando-se na expiração, aumento maior que duas vezes o valor registrado na inspiração, também é sugestivo de compressão do tronco celíaco. A manutenção de VPS elevadas na inspiração e expiração indicam a presença de estenose fixa da artéria ${ }^{42}$.

\subsection{Tomografia Computadorizada/Angiotomografia}

As imagens obtidas em angiotomografia apresentam qualidade e similaridade comparáveis à arteriografia convencional, substituindo atualmente este exame, sobretudo no planejamento pré-operatório, além de fornecer informações adicionais ${ }^{9,10}$. Aparelhos de tomografia com múltiplas fileiras de detectores permitem a obtenção de cortes milimétricos, em curto intervalo temporal, com volume de dados isotrópicos, de alta resolução espacial, permitindo a reconstrução da imagem em múltiplos planos, renderização de volume em três dimensões e uso de técnicas como projeção de máxima intensidade (MIP). 
A tomografia permite a identificação de outros processos eventualmente responsáveis pela sintomatologia do paciente, como tumores ou quadros inflamatórios abdominais. Os achados tomográficos da compressão do tronco celíaco são os mesmos descritos previamente em exames angiográficos convencionais, sobretudo observados nas reconstruções sagitais: estenose assimétrica focal ou indentação no aspecto superior do tronco celíaco; presença de dilatação pós-estenose; deslocamento inferior do tronco seguida de angulação cranial assumindo aspecto em J, $U$ ou gancho e colateralização pela arcada pancreatoduodenal. A tomografia permite ainda a visualização direta do ligamento arqueado, que pode apresentar-se espessado $>4 \mathrm{~mm}$ em seu cruzamento junto à origem do TC. Adicionalmente lesões ateroscleróticas podem ser distinguidas pela visualização de placas ou irregularidades parietais nos vasos adjacentes (aorta e demais vasos viscerais) ${ }^{43-48}$. Outras causas de compressão extrínseca como invasão tumoral ou metástases linfonodais também podem ser identificadas à tomografia. Da mesma forma que nos exames arteriográficos, a aquisição de imagens tomográficas durante a fase expiratória pode evidenciar ou acentuar compressão do tronco quando presente ${ }^{49}$.

Por tratar-se de método menos invasivo que a arteriografia, e mais completo do ponto de vista de anatomia que o ultrassom doppler, a tomografia computadorizada tem sido o exame de escolha para investigação diagnóstica de pacientes com suspeita de insuficiência arterial visceral, como na síndrome do ligamento arqueado mediano. 
Na prática clínica, admite-se como indicativo de compressão do TC pelo LAM o sinal do gancho nas imagens de tomografia em reconstrução sagital e presença de estenose da artéria.

\subsection{Ressonância Magnética/Angiorressonância}

Exames de ressonância magnética podem ser utilizados para avaliação da doença oclusiva arterial mesentérica, apresentando alta sensibilidade e especificidade para identificar estenoses proximais do TC a AMS, comparáveis a exames de angiotomografia, porém com menor resolução espacial e limitações para ramos de menor calibre e $\mathrm{AMI}^{50}$. Diferentes técnicas de exame são possíveis, com melhores resultados obtidos ao administrar contraste paramagnético e pós processamento com reconstrução tridimensional. Técnicas mais antigas, como o time-offlight apresentam tempo de aquisição prolongado, são mais susceptíveis a artefatos de movimento e podem superestimar estenoses ${ }^{51}$.

A compressão do TC é melhor observada em projeções sagitais, assim como nas angiotomografias, e consiste na observação de indentação no aspecto superior da artéria, com acentuação durante a expiração. Por apresentar limitação na identificação de calcificações dos vasos, a diferenciação de estenoses de etiologia aterosclerótica ou por compressão pelo LAM pode não ser possível em exames de angioressonância9 . 
Apesar de constante evolução das técnicas de ressonância, possibilitando menor tempo de aquisição de imagens, redução de artefatos de movimento e progressiva melhora das resoluções espaciais, ainda é um exame de maior custo, menor disponibilidade, e que demanda maior tempo para sua realização, se comparado à angiotomografia.

\subsection{Fisiopatologia}

Existe controvérsia a respeito da fisiopatologia dos sintomas apresentados pelos pacientes portadores de compressão do tronco celíaco. A ausência de uma explicação plenamente satisfatória para a fisiopatologia dos sintomas e, resultados variáveis na melhora dos sintomas em pacientes submetidos à descompressão cirúrgica do tronco, com ocorrência significativa de recorrências, levou Szilagyi et al. ${ }^{8}$ a questionar a existência da síndrome. Nos primeiros relatos da síndrome e estudos arteriográficos, os autores já recomendavam prudência no diagnóstico e na instituição do tratamento. O achado de sinais de compressão/estenoses em frequência significativa de pessoas assintomáticas, também reforça necessidade de cautela ao se indicar o tratamento.

Quatro teorias são propostas para explicar a gênese dos sintomas:

a) Origem neuropática: esta teoria atribui a dor ao efeito de compressão sobre o plexo ganglionar, anatomicamente relacionado ao LAM (e por vezes, o próprio complexo ganglionar constituindo uma massa fibrosa constringindo o TC), sofrendo irritação ou fricção durante os batimentos arteriais. Também foi aventado o mecanismo de estímulo das fibras 
simpáticas localmente, levando à vasoconstrição e provocando dor de caráter isquêmico. Os primeiros relatos de Harjola $^{1}$ e a realização de exame anatomopatológico do tecido proveniente da área descomprimida cirurgicamente atribuem ao complexo neural local a ocorrência de compressão da artéria ${ }^{6}$. No entanto Marable et al. ${ }^{4}$ sustentam que ao se realizar a descompressão, a extensão da neurólise que é efetivamente obtida não constitui uma denervação suficiente para justificar a melhora dos sintomas. Além disso, o caráter pós-prandial da dor não é compatível com uma situação de irritação contínua das fibras nervosas.

b) Isquemia do intestino, provocada por hipofluxo secundário à compressão do tronco celíaco: neste caso, a crítica principal se baseia no entendimento de que, para a ocorrência de isquemia mesentérica e sintomatologia associada, seria necessário o acometimento de dois ou mais vasos viscerais, devido a ampla rede de anastomoses/colateralização existente entre os três principais vasos mesentéricos. Tal fato é comumente observado na doença aterosclerótica mesentérica crônica, onde a lesão isolada de uma artéria muitas vezes é tolerada ou mesmo não produz sintomas. Além disso a ligadura do tronco celíaco frequentemente é suportada no trauma ou em cirurgias oncológicas. A teoria é suportada pelo fato de muitas vezes não ser observada colateralização desenvolvida entre o TC e AMS, podendo ocorrer uma isquemia regional da porção proximal do intestino. No entanto, estudo de Szilagy et al. ${ }^{8}$ relataram, em 157 arteriografias, o achado de estenoses do TC em grau variável, sem que se identificasse qualquer correlação entre o grau de estenose, presença ou 
ausência de colaterais e a ocorrência de sintomas abdominais. Além disso, comumente os gradientes pressóricos entre aorta e tronco celíaco após a estenose não se mostram elevados.

c) Roubo de fluxo do território da AMS: nesta situação, a presença de colaterais largamente desenvolvidas na arcada pancreatoduodenal, comunicando o território do TC estenótico/ocluído com o território da AMS, poderia levar a fenômeno de roubo de fluxo para as porções proximais do intestino durante os períodos de ingesta alimentar, com consequente diminuição do fluxo para os demais territórios nutridos pela AMS distalmente, levando à ocorrência de dor de caráter isquêmico/pós-prandial ${ }^{36}$. Entretanto estudos fisiológicos mostram que no período prandial e pós-prandial há aumento global do fluxo em todo o leito intestinal ${ }^{52}$.

d) Compressão concomitante da AMS: esta condição pode ser encontrada em casos de compressão do TC, acometendo também a AMS ou mesmo artéria renal ${ }^{39}$, em virtude da proximidade anatômica da origem destas artérias. O LAM ou mesmo a própria crura esquerda podem se projetar mais inferiormente exercendo efeito de compressão também sobre a AMS. Neste caso, o acometimento de dois vasos viscerais poderia justificar os sintomas ${ }^{53-55}$.

Desta forma observa-se a ausência de clara explicação fisiopatológica para a ocorrência dos sintomas da compressão extrínseca do tronco celíaco. A constatação de sinais radiológicos de compressão do TC em indivíduos assintomáticos, parece mostrar uma dissociação entre o fenômeno anatômico de compressão e presença de sintomatologia. Apesar da 
disponibilidade crescente de exames tomográficos levar à observação mais frequente destes sinais, o significado e importância dos mesmos nestes indivíduos é desconhecida, e tampouco sua relação com a anatomia normal.

Considerando a controvérsia quanto ao real significado clínico desta condição anatômica, um dos objetivos deste estudo foi investigar o valor do sinal de gancho para o diagnóstico de compressão pelo LAM, estudando a prevalência do mesmo num grupo de indivíduos saudáveis, como os doadores renais. 


\section{Objetivos}


a) Avaliar a anatomia do tronco celíaco e sua relação com o ligamento arqueado mediano em angiotomografia computadorizada de pacientes sem sintomas de compressão do tronco celíaco.

b) Analisar possíveis variações dos parâmetros anatômicos em relação a dados antropométricos como sexo, idade, peso, altura e índice de massa corpórea.

c) Identificar a prevalência de estenose do tronco celíaco nesta população.

d) Apontar a prevalência do sinal do gancho nos indivíduos com estenose do tronco celíaco. 
3 MÉtodos 
Trata-se de um estudo anatômico descritivo. Foram analisadas retrospectivamente imagens de angiotomografia de 344 indivíduos assintomáticos, obtidas no sistema Picture Archiving and Communication System (PACS) do Hospital das Clínicas da Faculdade de Medicina da Universidade de São Paulo (HCFMUSP). A amostra populacional constituiuse de doadores renais do programa de transplante renal intervivos da instituição, totalizando 222 mulheres e 122 homens, com idades entre 24 e 66 anos e mediana de 38 anos. As nefrectomias nestes doadores foram realizadas no período de janeiro de 2010 a outubro de 2014. Tais doadores são submetidos à extensa avaliação clínica, obtidos dados antropométricos, e realizados exames complementares como parte do protocolo de préseleção de doadores; e não apresentavam história prévia de dor abdominal que justificasse queixa espontânea ou perda ponderal. Os doadores em potencial passam por múltiplas consultas, com exclusão na primeira triagem daqueles que apresentam motivos de recusa para doação, como presença de hipertensão arterial, diabetes, incompatibilidade de grupo sanguíneo, obesidade (com índice de massa corpórea maior que $32 \mathrm{~kg} / \mathrm{m}^{2}$ ). Nefrolitíase, presença de neoplasias, ou síndromes genéticas que predispõe à insuficiência renal crônica também são motivos de exclusão de doadores. Foram utilizados registros médicos de prontuário do HCFMUSP e de prontuário informatizado do serviço de Transplante Renal da instituição. 
O estudo foi aprovado pelo Comitê de ética em pesquisa (CEP)/Comitê de Ética para Análise de Projetos de Pesquisa (CAPPesq) da instituição em parecer consubstanciado sob o número 816.000. Consentimento informado foi dispensado em virtude do uso de registro médico já existente, da ausência de intervenção proposta e de não identificação dos indivíduos (Anexo A).

As tomografias foram realizadas em equipamentos de 16 ou 64 canais (Lightspeed 16 e Discovery CT750HD) (GE Medical Systems, Milwaukee, Wisconsin, USA), segundo o protocolo de estudo de doadores renais, com aquisição de imagens em fase pré-contraste e pós-contraste fracionadas em fase arterial, venosa e excretora. Todas as aquisições foram realizadas em fase inspiratória, com reconstruções de $2 \mathrm{~mm}$. Cortes axiais e reconstruções sagitais foram utilizados em análises e medidas do tronco celíaco com uso de software dedicado de imagens no formato DICOM (OsiriX) (Pixmeo SARL, Geneva, Switzerland). Nas reconstruções sagitais foram mensurados: 1) ângulo de emergência do tronco celíaco em relação à aorta (pela medida do ângulo entre a borda inferior do tronco e borda anterior da aorta) (Figura 3); 2) ângulo de inclinação cranial ou caudal do tronco celíaco antes de emitir seu primeiro ramo (assim denominado ângulo de dobra) (Figura 4); e 3) presença de estenose $>50 \%$ da luz do tronco celíaco em sua porção proximal. Nas reconstruções sagitais também foram observadas a correlação da altura de origem do tronco celíaco e da margem inferior do ligamento arqueado mediano em relação às vértebras e espaços intervertebrais. Dados adicionais como presença de dilatação pós- 
estenótica, presença de colaterais desenvolvidas da arcada pancreatoduodenal, ocorrência de aneurismas da arcada pancreatoduodenal, calcificações junto ao óstio de origem do tronco celíaco também foram observados. Dados antropométricos de altura, peso e índice de massa corpórea (IMC) foram obtidos dos dados de prontuário e correlacionados com ângulos aferidos.

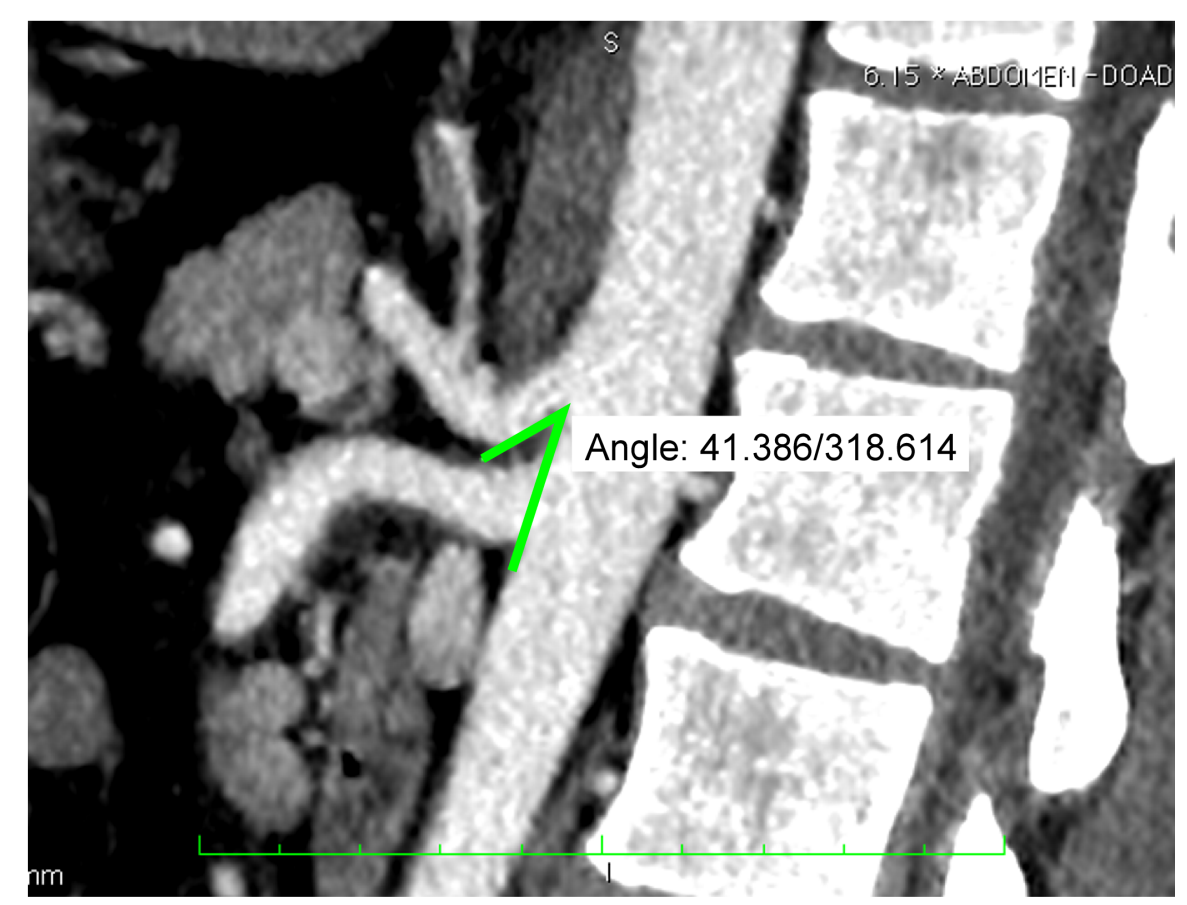

Figura 3 - Mensuração do ângulo de emergência. Reconstrução sagital. 


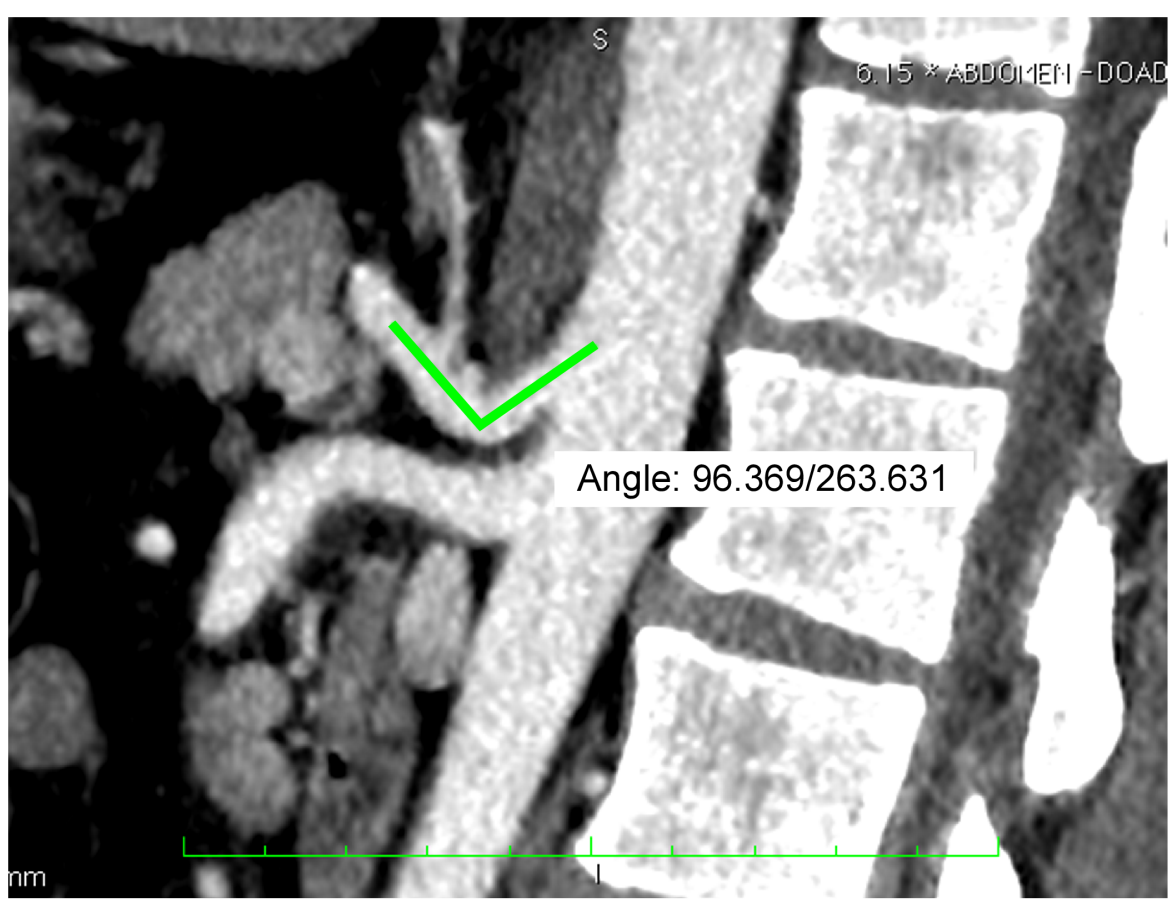

Figura 4 - Mensuração do ângulo de dobra. Reconstrução sagital.

\subsection{Análise Estatística}

Teste de Shapiro-Wilk foi realizado para verificar padrão de distribuição dos dados obtidos, observando-se distribuição não normal para a maior parte das variáveis. Dessa forma, testes não paramétricos foram empregados para as análises subsequentes.

As comparações de idade, dados antropométricos e ângulos medidos entre homens e mulheres foram realizadas utilizando-se teste de MannWhitney U.

Correlações dos ângulos de emergência e dobra com idade e parâmetros antropométricos foram analisados utilizando-se correlação de coeficiente de Spearman. Para todas as análises $p<0,05$ foi utilizado como parâmetro de significância e os dados são apresentados como medianas com intervalo de confiança de 95\%. 
4 Resultados 
Imagens de angiotomografias de 344 doadores renais vivos consecutivos foram revistas. Em 21 doadores as imagens não estavam disponíveis no sistema PACS intra-hospitalar ou não apresentavam qualidade suficiente para análise e foram excluídas da série. Em dois casos o tronco celíaco era ausente, com artéria hepática, gástrica esquerda e esplênica originando-se diretamente da aorta. A amostra final constituiu-se, portanto, de 321 indivíduos para análise. A idade variou de 24 a 66 com mediana de 39 anos; 114 doadores do sexo masculino, e 207 do sexo feminino.

Analisando-se a distribuição de idade, peso, altura e IMC entre homens e mulheres, observa-se diferença estatisticamente significante para os três primeiros dados: homens eram mais jovens, de peso e altura maiores quando comparados às mulheres. Não houve diferença significativa do IMC entre os dois grupos (Tabela 1).

\section{Tabela 1 - Dados antropométricos dos 321 doadores de acordo com o sexo}

\begin{tabular}{lccc} 
& $\begin{array}{c}\text { Homens } \\
(\mathbf{n}=114)\end{array}$ & $\begin{array}{c}\text { Mulheres } \\
(\mathbf{n = 2 0 7})\end{array}$ & $\mathbf{p}$ \\
\cline { 2 - 3 } & Mediana (IC 95\%) & Mediana (IC 95\%)) & \\
\hline Idade, anos & $36,0(36,1-39.4)$ & $40,0(39,1-41,5)$ & 0,03 \\
Peso, kg & $75,6(73,6-78.0)$ & $66,2(65,4-68.2)$ & $<0,01$ \\
Altura, cm & $172(170-173)$ & $160(159-161)$ & $<0,01$ \\
Índice massa corpórea, $\mathrm{kg} / \mathrm{m}^{2}$ & $25,7(25,1-26.3)$ & $25,9(25,5-26,4)$ & 0,76 \\
\hline
\end{tabular}

IC 95\%: intervalo de confiança de $95 \%$. 
Os valores dos ângulos de dobra e emergência do tronco celíaco também não apresentaram diferença significativa entre os sexos (Tabela 2). Não houve correlação entre os valores dos ângulos aferidos e idade.

\section{Tabela 2 - Valores dos ângulos de dobra e emergência em doadores homens e mulheres}

\begin{tabular}{lccc} 
& Homens $(\mathbf{n = 1 1 4})$ & Mulheres $(\mathbf{n = 2 0 7})$ & \\
\cline { 2 - 3 } & Mediana $($ IC 95\%)) & Mediana $($ IC 95\%) & \\
Ângulo dobra, graus & $143,5(137,2-145,7)$ & $145,8(141,8-148,4)$ & 0,12 \\
Ângulo emergência, graus & $28,7(28,0-28,5)$ & $28,5(27,0-31,3)$ & 0,89 \\
\hline
\end{tabular}

IC $95 \%$ : intervalo de confiança de $95 \%$.

O tronco celíaco apresentou ângulo de emergência da aorta variando entre 7 e 83 graus, com mediana de 28 graus, ou seja, ângulo $<90$ graus em todos os indivíduos da amostra e menor que 45 graus em 292 dos 321 $\operatorname{casos}(90 \%)$.

O ângulo de dobra variou de 66 a 208 graus, com mediana de 143,5 graus. Antes de seu primeiro ramo, o tronco celíaco apresentou desvio cranial em 306 dos 321 casos (95\%), desvio caudal em 14/321 (4,36\%) ou manteve-se retilíneo, sem desvio de seu percurso em 1/321.

Os coeficientes de correlação entre os ângulos aferidos e dados antropométricos em homens e mulheres são demonstrados na Tabela 3.

Tabela 3 - Correlação de Spearman entre os ângulos aferidos e parâmetros clínicos

\begin{tabular}{ccccccccc} 
& \multicolumn{3}{c}{ Homens } & \multicolumn{4}{c}{ Mulheres } \\
\cline { 2 - 9 } & $\begin{array}{c}\text { Ângulo de } \\
\text { dobra }\end{array}$ & \multicolumn{2}{c}{$\begin{array}{c}\text { Ângulo de } \\
\text { emergência }\end{array}$} & $\begin{array}{c}\text { Ângulo } \\
\text { de dobra }\end{array}$ & \multicolumn{2}{c}{$\begin{array}{c}\text { Ângulo de } \\
\text { emergência }\end{array}$} \\
\cline { 2 - 10 } & rho & $\mathbf{p}$ & rho & $\mathbf{p}$ & rho & $\mathbf{p}$ & rho & $\mathbf{p}$ \\
\hline Peso & $-0,295$ & $<0,01$ & 0,126 & 0,18 & $-0,227$ & $<0,01$ & 0,209 & $<0,01$ \\
Altura & $-0,083$ & 0,38 & $-0,181$ & 0,06 & $-0,095$ & 0,18 & $-0,09$ & 0,2 \\
Idade & 0,116 & 0,22 & 0,144 & 0,12 & 0,129 & 0,06 & 0,012 & 0,87 \\
\hline
\end{tabular}

rho: coeficiente de correlação de Spearman. 
O ângulo de emergência foi positivamente correlacionado com o peso em mulheres; mulheres com maior peso apresentavam ângulos maiores de emergência. O ângulo de dobra, por sua vez, apresentou correlação negativa com o peso em homens e mulheres; quanto maior o peso, menores os ângulos observados.

Houve correlação negativa entre IMC e ângulo de dobra em homens e mulheres, e correlação positiva entre IMC e ângulo de emergência em homens e mulheres (Gráfico 1).

Gráfico 1 - Correlação entre os dados antropométricos de IMC e ângulos aferidos em homens e mulheres

\section{Sexo Masculino}

a

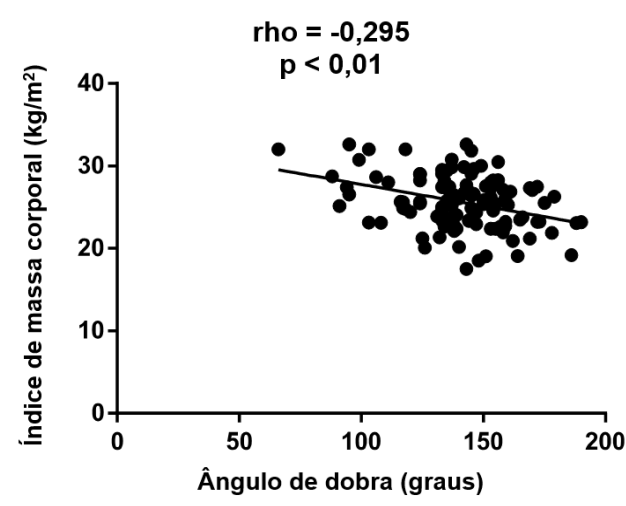

SEXo Feminino b

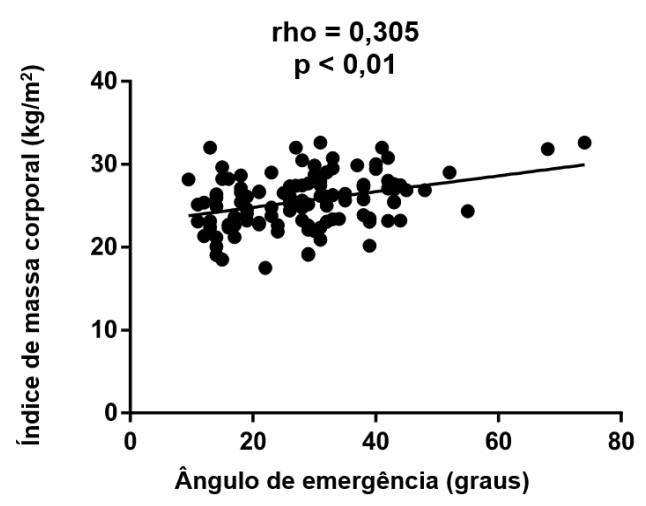

C

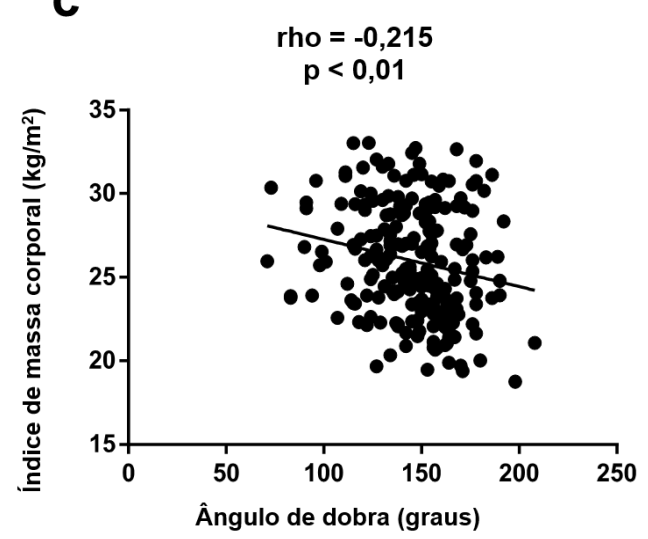

d

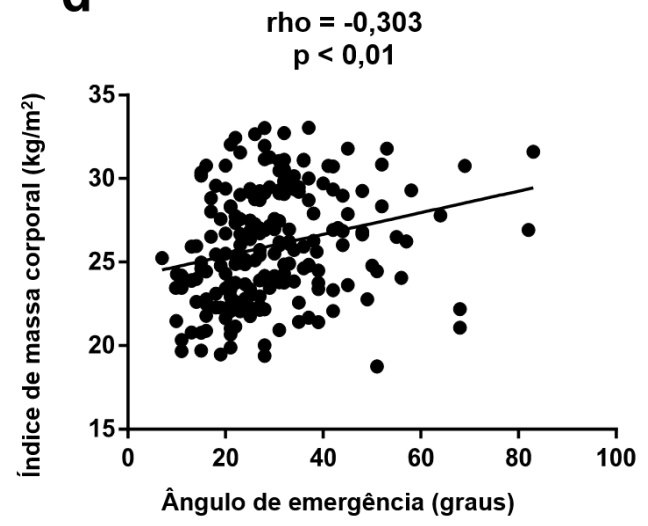


Ao analisar a relação entre altura de origem do tronco celíaco e margem inferior do ligamento arqueado mediano observou-se a margem inferior do LAM abaixo da origem do tronco em 136 (42,36\%) doadores; no mesmo nível em 144 (44,85\%), e acima em 41 (12,77\%). O histograma abaixo mostra a frequência de distribuição da origem do tronco celíaco e da margem inferior do LAM em relação aos corpos vertebrais.

Gráfico 2 - Distribuição das alturas de origem do tronco celíaco (vermelho) e margem inferior do ligamento arqueado mediano (azul), em relação às vértebras

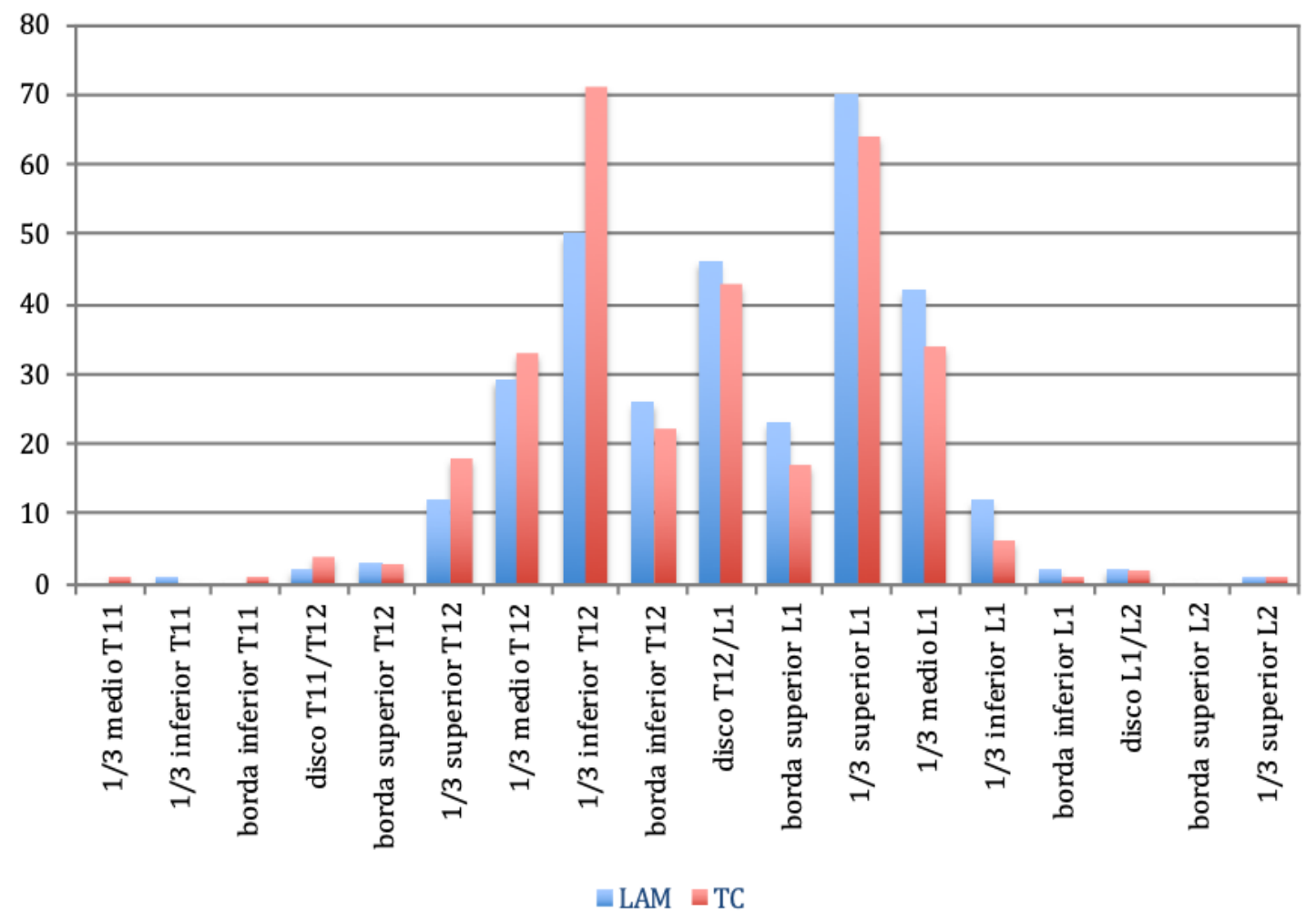

Estenose do tronco celíaco em sua porção proximal, definida como estreitamento maior que $50 \%$ de sua luz, foi encontrada em 11 casos $(3,4 \%)$, sendo observada dilatação pós-estenótica em sete. O trajeto inicial do vaso apresentou desvio cranial acentuado (ângulo de dobra < 90\%) após a estenose, interpretado como sinal de gancho, em dois desses casos $(0,62 \%$ 
do total de doadores), um deles apresentando dilatação pós-estenótica (Figuras 5 a 8). Esse mesmo desvio cranial acentuado foi encontrado em quatro outros doadores da amostra, sem apresentar estenose. Evidência de colateralização através da arcada pancreaticoduodenal foi observada em três dos 11 casos, nenhum deles apresentando aspecto de gancho. O IMC variou de $17,5 \mathrm{~kg} / \mathrm{m}^{2}$ a $32 \mathrm{~kg} / \mathrm{m}^{2}$, e nove desses casos de estenose $>50 \%$ eram do sexo feminino. A margem inferior do LAM apresentou-se abaixo da origem do tronco celíaco em nove dos 11 casos de estenose, com a origem do mesmo totalmente coberta pelo ligamento. Dados desses doadores com estenose são apresentados na Tabela 4.

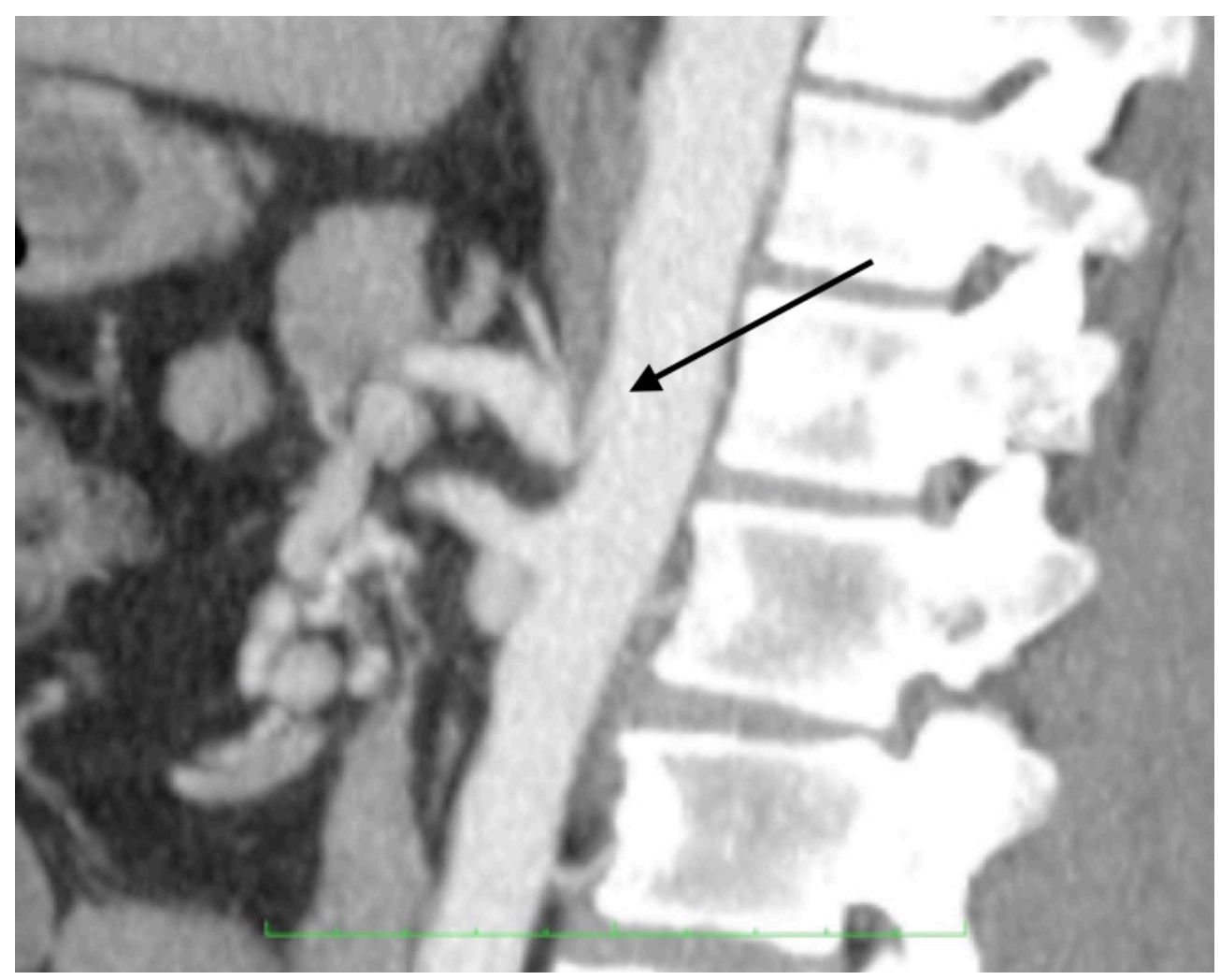

Figura 5 - Estenose do tronco celíaco com aspecto em gancho. 


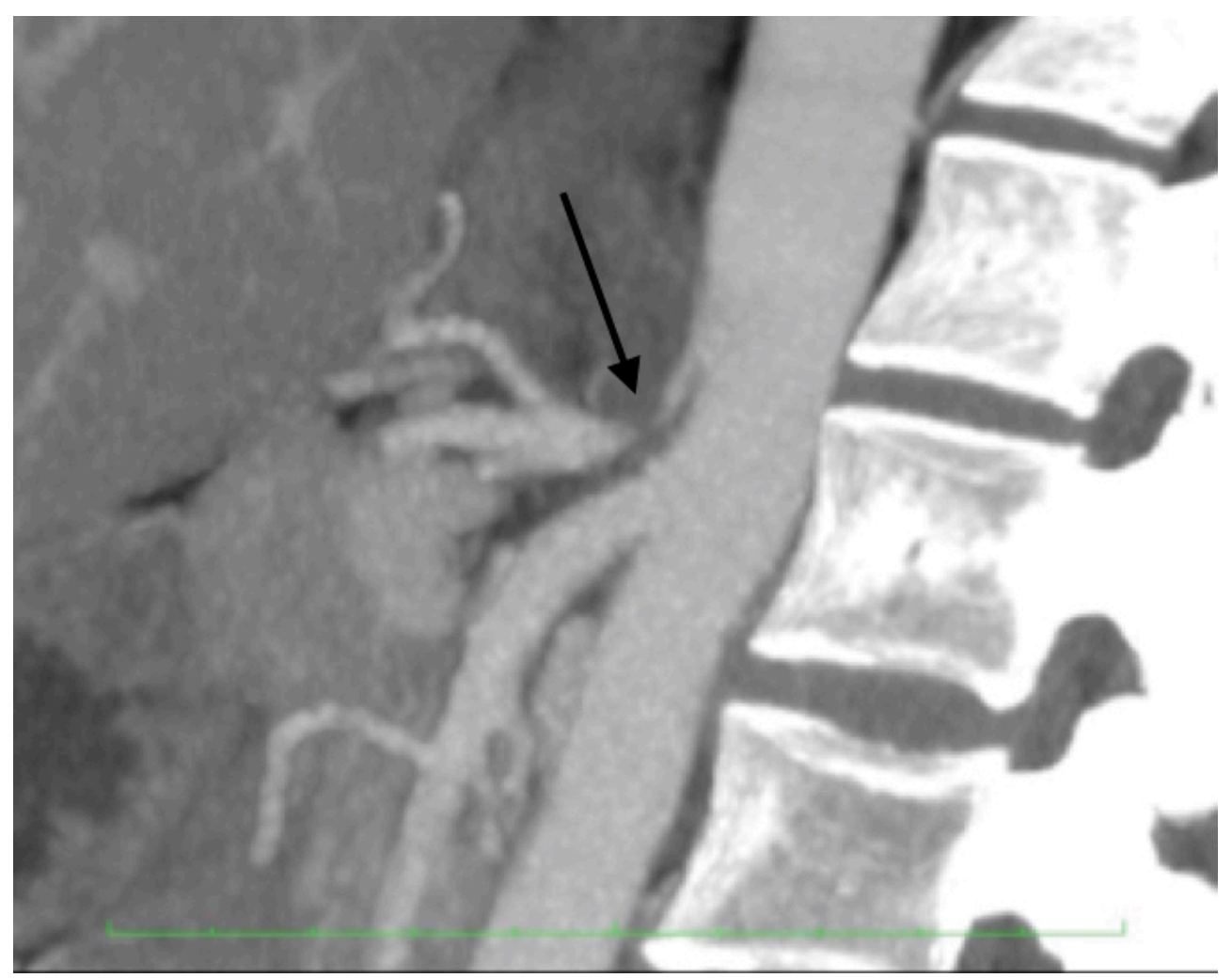

Figura 6 - Estenose crítica/suboclusão do tronco celíaco

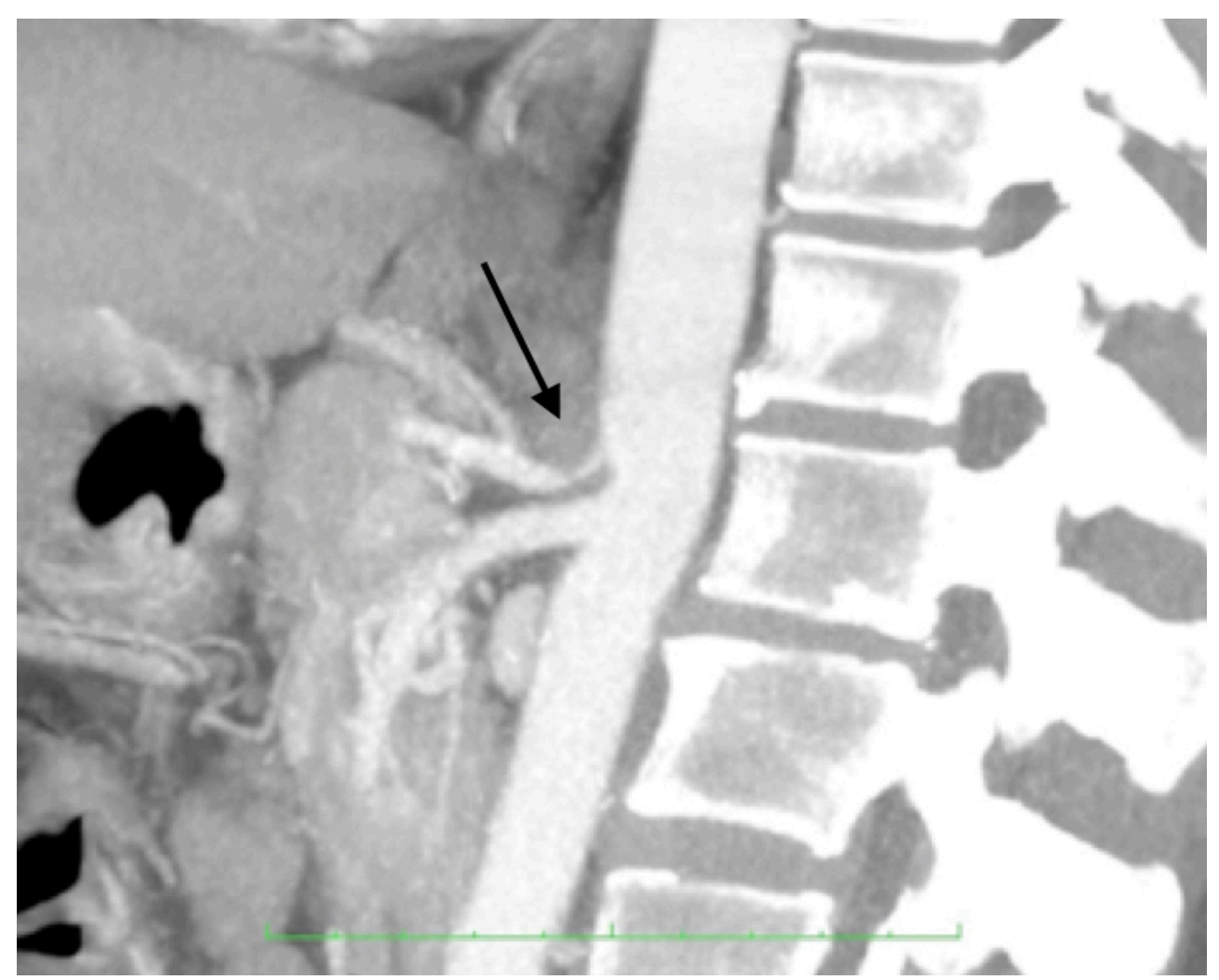

Figura 7 - Estenose crítica do tronco celíaco, ausência de aspecto em gancho 


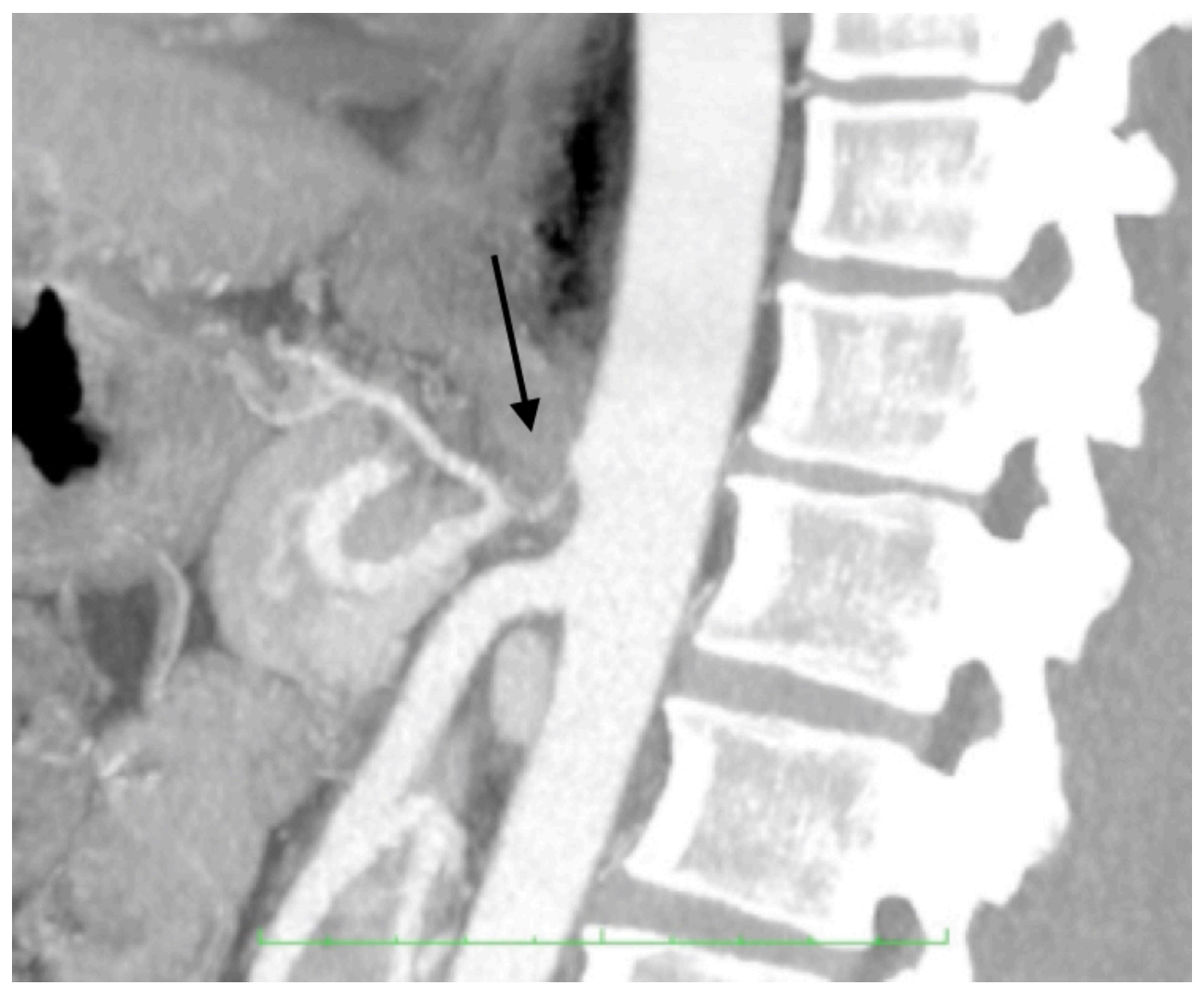

Figura 8 - Suboclusão do TC, LAM projetando-se sobre sua origem 
Tabela 4 - Características anatômicas e dados demográficos dos doadores com estenose do tronco celíaco $>50 \%$

\begin{tabular}{|c|c|c|c|c|c|c|c|c|c|c|}
\hline Doador & Idade & Sexo & IMC & AE & AF & $\begin{array}{c}\text { Colateralização } \\
\text { pela arcada } \\
\text { pancreatoduodenal }\end{array}$ & $\begin{array}{l}\text { Altura } \\
\text { do LAM }\end{array}$ & $\begin{array}{l}\text { Altura da } \\
\text { origem } \\
\text { do TC }\end{array}$ & $\begin{array}{c}\text { Relação } \\
\text { entre altura } \\
\text { do LAM e } \\
\text { origem do TC }\end{array}$ & $\begin{array}{c}\text { Dilatação } \\
\text { pós-estenótica }\end{array}$ \\
\hline 1 & 61 & Feminino & 23,45 & 9,8 & 148 & - & Terço superior L1 & Terço inferior T12 & Abaixo & + \\
\hline 2 & 47 & Feminino & 23,91 & 11 & 94 & + & Borda superior L1 & Terço inferior T12 & Abaixo & + \\
\hline 3 & 37 & Feminino & 17,52 & 22 & 143 & - & Terço médio L1 & Terço médio L1 & Mesmo nível & - \\
\hline 4 & 62 & Feminino & 23,1 & 18 & 168 & - & Terço superior L1 & Borda inferior T12 & Abaixo & + \\
\hline 5 & 44 & Feminino & 30 & 37 & 124 & + & Terço médio L1 & Terço superior L1 & Abaixo & + \\
\hline 6 & 29 & Feminino & 27,34 & 22 & 146 & - & Terço inferior T12 & Terço inferior T12 & Mesmo nível & - \\
\hline 7 & 33 & Feminino & 23,45 & 11 & 115 & - & Terço médio L1 & Borda superior L1 & Abaixo & + \\
\hline 8 & 29 & Masculino & 23,67 & 24 & 150 & - & Terço inferior L1 & Terço médio L1 & Abaixo & + \\
\hline 9 & 43 & Feminino & 27,88 & 45 & 131 & + & Terço médio L1 & Terço superior L1 & Abaixo & - \\
\hline 10 & 41 & Masculino & 32,02 & 13 & 66 & - & Disco T12/L1 & Borda inferior T12 & Abaixo & + \\
\hline 11 & 40 & Feminino & 23,87 & 13 & 83 & - & Terço superior L1 & Borda inferior T12 & Abaixo & - \\
\hline
\end{tabular}

IMC: índice de massa corpórea; AE: ângulo de emergência, AD: ângulo de dobra; LAM: ligamento arqueado mediano; TC: tronco celíaco; L1: ${ }^{a}$ vértebra lombar; T12: $12^{\mathrm{a}}$ vértebra torácica; +: presente; -: ausente. 
5 Discussão 
A anatomia habitual do tronco celíaco em sua porção inicial não é descrita em estudos tomográficos, sendo relatados somente variações de suas ramificações e achados patológicos como a ocorrência de compressão pelo ligamento arqueado, identificada pela presença de estenose proximal do tronco e morfologia de seu trajeto inicial. Descrever o comportamento e aspecto anatômico do tronco celíaco em sua porção proximal, utilizando-se de tomografias em uma série de indivíduos saudáveis, auxilia a estabelecer um padrão de normalidade, definindo parâmetro de comparação com morfologias consideradas até então anormais. O presente estudo estabelece características anatômicas mais frequentemente encontradas, descrevendo a morfologia habitual do tronco celíaco, além de verificar a ocorrência de compressão em uma população considerada saudável. Doadores renais vivos constituem indivíduos saudáveis que são submetidos à angiotomografia como parte do protocolo pré-operatório de doação, proporcionando de modo conveniente exames que não seriam eticamente realizáveis em população assintomática somente a pretexto de estudo, por envolver riscos relacionados ao uso de contraste, radiação ionizante e custos adicionais ao sistema de saúde.

$\mathrm{Na}$ presente casuística de 321 angiotomografias de indivíduos assintomáticos, foi encontrada uma prevalência de 3,4\% (11 doadores) de estenoses do tronco celíaco atribuíveis à compressão pelo ligamento 
arqueado mediano, compatível com dados de literatura. A incidência de compressão em angiotomografias de pacientes assintomáticos varia de $2,8 \%$ a $5,1 \%{ }^{56,57}$. No entanto os critérios para determinar presença de compressão nos diferentes estudos não são uniformes.

Em estudo com 200 pacientes sem queixas abdominais submetidos à ultrassonografia Doppler, aqueles com aumento de VPS $>200 \mathrm{~cm} / \mathrm{s}$ no tronco celíaco em expiração ou velocidade duas ou mais vezes maior que seu valor em inspiração eram submetidos a estudo tomográfico adicional. Foram considerados portadores de compressão aqueles com achado de contorno em gancho ou estenose focal proximal associada à presença de dilatação pós-estenótica com ou sem colateralização, totalizando oito pacientes (4\%). Nenhum apresentava colateralização proeminente ou oclusão nas imagens tomográficas ${ }^{42}$.

Em outro estudo retrospectivo de 744 pacientes submetidos à tomografia por variadas indicações, compressão foi encontrada em 21 pacientes $(2,8 \%)$, entre os quais 18 assintomáticos. Foram utilizados como critérios para diagnóstico de compressão hipertrofia/espessamento da crura, estenose proximal e deslocamento inferior e posterior do tronco celíaco ${ }^{56}$.

Em série com 400 pacientes referenciados para procedimentos de quimioembolização de tumores hepáticos, compressão do tronco celíaco pelo LAM foi relatada em $16(4 \%)$ indivíduos. Neste estudo, dados de arteriografia e tomografia foram utilizados, com critérios de estenose $>50 \%$ e gradiente pressórico > $10 \mathrm{mmHg}$ para significância da estenose e definição da etiologia utilizando-se aspecto com angulação aguda do tronco celíaco em direção inferior e presença de incisura em seu aspecto superior ${ }^{58}$. 
Em população semelhante ao presente estudo, porém com casuística menor, tomografias de 155 doadores renais saudáveis e assintomáticos foram retrospectivamente analisadas. Os critérios para compressão do tronco celíaco foram estenose $>50 \%$ em imagens axiais e aparência de gancho em reconstruções sagitais. Adicionalmente foram observados o nível inferior do LAM em relação às vertebras, presença de colaterais e dilatação pós-estenótica. Oito doadores $(5,1 \%)$ apresentavam os critérios para compressão. A origem do tronco encontrava-se acima de L1 nestes pacientes, com seis deles apresentando borda inferior do LAM abaixo de L1. Dilatação após estenose foi observada somente em três $(1,9 \%)$ e ausência de colaterais em todos ${ }^{57}$. Na presente casuística, todos os casos de estenose apresentaram a origem do tronco acima ou no mesmo nível do LAM, com dilatação pós-estenótica em sete doadores $(2,18 \%)$ e presença de redes colaterais desenvolvidas em somente três $(0,93 \%)$. Embora seja sugerido que a ausência de sintomas em indivíduos com estenose possa ser explicada pela presença de colateralização desenvolvida na arcada pancreaticoduodenal, a presente casuística e a relatada acima não mostram correlação entre ocorrência de colaterais e ausência de sintomas; reafirmando a complexidade da fisiopatologia dos sintomas. A mesma conclusão é feita por Szilagy et al. ${ }^{8}$, observando não haver correlação entre grau de estenose, presença ou ausência de colaterais e sintomas de dor abdominal ou perda ponderal.

$\mathrm{Na}$ presente amostra, nove entre os 11 casos de estenose/compressão ocorreram em indivíduos do sexo feminino. A 
síndrome de compressão do tronco celíaco pelo LAM parece acometer principalmente mulheres entre 20-50 anos ${ }^{43}$. No estudo anatômico de Lindner e Kemprud $^{18}$, os mesmos relatam que existe uma maior proximidade entre a origem do TC e o LAM em mulheres, também apresentando posicionamento mais alto das duas estruturas em relação aos corpos vertebrais, o que justificaria maior incidência da síndrome em mulheres.

Estudos com imagens de arteriografia de lesões em tronco celíaco mostram uma distribuição da etiologia aterosclerótica em faixas etárias mais elevadas $^{24}$. Na presente casuística, a mediana de idade foi de 39 anos (36 em homens e 40 em mulheres), e não foram encontradas estenoses relacionadas à doença aterosclerótica, refletindo a população saudável de doadores renais. Além disso, a faixa etária de doadores renais não é a comumente observada em pacientes com aterosclerose, mais idosos.

A origem do tronco celíaco apresentou maiores frequências de localização entre o 1/3 superior de T12 e 1/3 médio de L1; enquanto a borda inferior do LAM entre 1/3 médio de T12 e 1/3 médio de L1, demonstrando variabilidade e localização em consonância com estudos anatômicos e radiológicos ${ }^{17,18}$. Dentre os 11 casos de estenose da presente amostra, nove apresentaram a origem do tronco celíaco acima do LAM, com os dois restantes no mesmo nível. Margem inferior do LAM abaixo da origem do tronco ou no mesmo nível correspondeu a $87 \%$ do total de doadores, demonstrando que não é situação incomum em população de indivíduos assintomáticos. Estudo de Katz-Summercorn e Bridger ${ }^{20}$ em 99 cadáveres mostrou não haver distância mensurável entre o TC e LAM em 92\%, com 
evidência de kinking ou compressão da artéria em 33\%. O TC se apresenta parcialmente coberto pelo LAM em $48 \%$ a $52 \%$ de espécimes cadavéricos, podendo constituir relação anatômica normal e comum ${ }^{18,19}$.

As medidas dos ângulos de interesse (emergência e dobra) em pacientes assintomáticos e saudáveis permite definir qual o padrão de conformação mais frequente do tronco celíaco em seu trajeto após emergência da aorta. De acordo com os dados obtidos, o tronco celíaco após sua emergência assume inicialmente uma curvatura em direção caudal, seguida de inflexão cranial, antes de sua primeira ramificação na maior parte dos indivíduos (Figura 9).

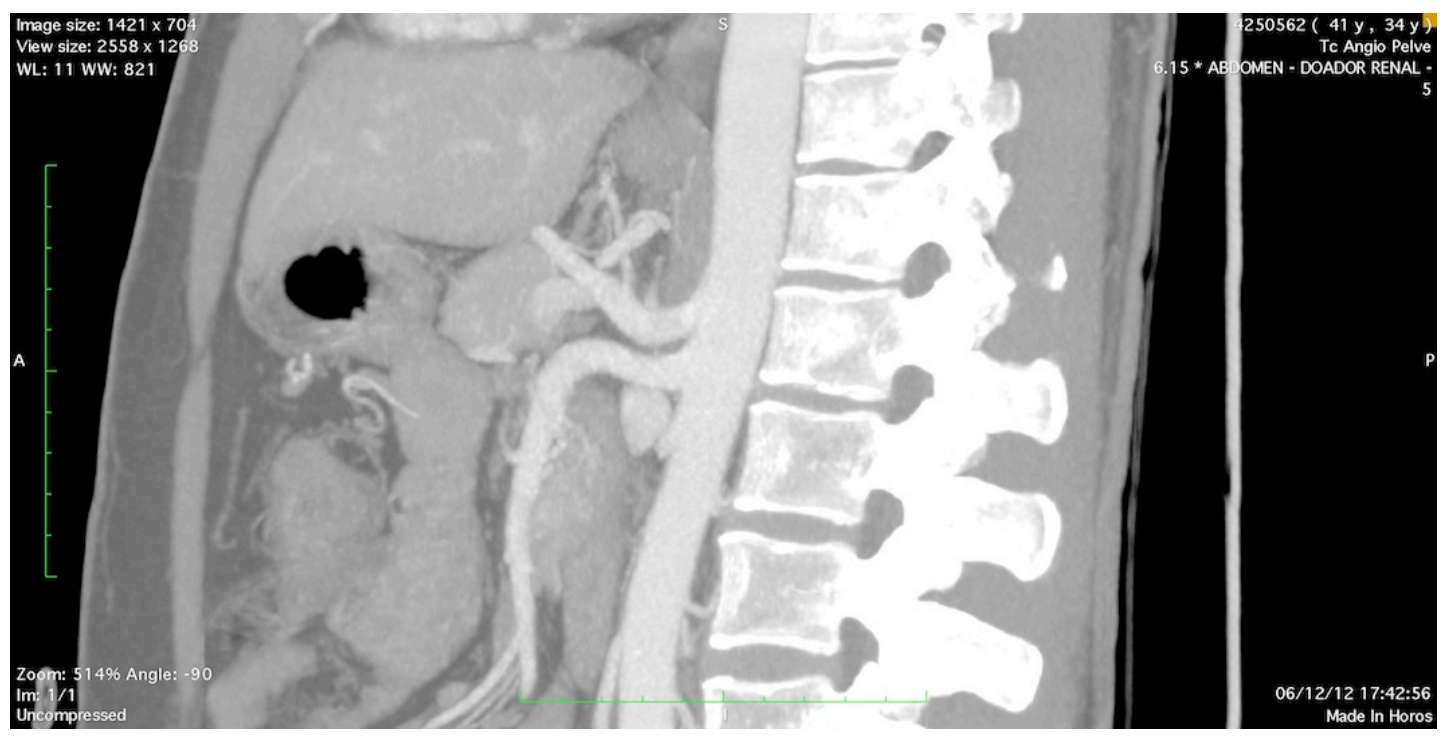

Figura 9 - Trajeto habitual do tronco celíaco

Os ângulos de emergência apresentaram-se $<45$ graus em 90\% da amostra (292/321), demonstrando o trajeto inicial caudal, com mediana de 28 graus; seguido de trajeto ascendente em 95\% dos doadores (306/321), com o ângulo de dobra apresentando mediana de 143 graus. Lindner e Kemprud $^{18}$ sugerem que o ângulo entre o TC e aorta (ângulo de 
emergência) parece diminuir com a idade, com achado de ângulos $<30$ graus, que apresentam aumento para mais de 50 quando realizada a liberação do LAM. Na presente amostra não foi observada correlação significativa entre os valores dos ângulos e a idade.

Dunbar et $a .^{3}$, ao relatarem a série de casos de compressão realizaram previamente estudo arteriográfico em projeção lateral em 25 pacientes sem queixas abdominais procurando estabelecer as relações normais do tronco celíaco. Descreveram que o ângulo entre a aorta e o TC varia de 90 graus a próximo de zero graus, seguido de curva cefálica; observando, ainda, que este ângulo se apresenta mais agudo em indivíduos magros, e que a curvatura cefálica parece ser mais acentuada em indivíduos obesos. Na presente casuística houve correlação positiva entre o ângulo de emergência e medida de gordura corporal, medido pelo IMC, com ângulos menores encontrados em indivíduos de menor IMC. A correlação entre peso isoladamente e ângulo de emergência foi significativa nas mulheres.

Ângulos de dobra menores, determinando maior inclinação cranial, mostraram correlação negativa com o IMC e peso, com indivíduos de maior peso apresentando ângulos de menor valor, dado compatível com a observação de Dunbar et al. ${ }^{3}$ em relação à curvatura cefálica do tronco. Tais observações parecem demonstrar a influência da composição corporal na conformação anatômica regional junto ao tronco celíaco.

Em estudo com ultrassonografia Doppler em 40 homens saudáveis, sem fatores de risco ou doença cardiovascular conhecida, observou-se correlação entre o IMC e medidas de VPS no tronco celíaco, com 
velocidades menores e diâmetros maiores do tronco em indivíduos com maior IMC. Os autores sugerem que essa diferença poderia ser explicada por maior calibre e maior quantidade de tecido adiposo acumulado junto ao tronco celíaco em indivíduos obesos, tornando-o menos susceptível à compressão pelo LAM ${ }^{59}$.

O sinal do gancho é citado classicamente em séries de pacientes sintomáticos como típico de compressão pelo LAM, com o tronco celíaco assumindo aspecto em $\mathrm{J}$ ou $\mathrm{U}$ em seu trajeto inicial, descrevendo um trajeto descendente seguido de curvatura ascendente ${ }^{5}$. Porém, tal sinal é observado com variável frequência em pacientes assintomáticos ${ }^{7,57,58} . \mathrm{Na}$ presente série de indivíduos saudáveis, conforme comentado anteriormente, a projeção sagital visualizada nas tomografias revelou que a conformação mais habitual do tronco celíaco é o seu trajeto descendente após origem da aorta, observada em todos os casos; seguida de desvio cranial, observado em 95\%. Esta conformação assemelha-se ao que é descrito como aspecto de gancho, podendo, no entanto, ser considerado a configuração anatômica normal do trajeto do tronco celíaco, não representando um achado patológico. O curso normal do tronco celíaco pode ser interpretado como um aspecto em gancho, com o citado sinal podendo corresponder a um extremo dessa anatomia normal, com ângulos mais agudos, tornando a distinção entre o que poderia ser denominado aspecto normal e patológico pouco clara e subjetiva. Ainda, a angulação caudal inicial do tronco celíaco, com ângulos mais agudos, tende a ser mais pronunciada em indivíduos de menor peso corpóreo e menor IMC. Dentre os 11 casos de estenose encontrados 
na presente casuística chamou a atenção o fato de que, em nove deles, curvatura caudal seguida de acentuado direcionamento cranial não foi observada; porém frequentemente observada na anatomia normal sem estenose ou compressão (Figura 10). Apenas dois indivíduos com estenose $>50 \%$ apresentaram imagem de acentuada curvatura interpretada como sinal de gancho $(0,6 \%$ da amostra total). Por outro lado, foram encontrados quatro indivíduos na amostra com acentuada curvatura sem qualquer estenose do tronco.
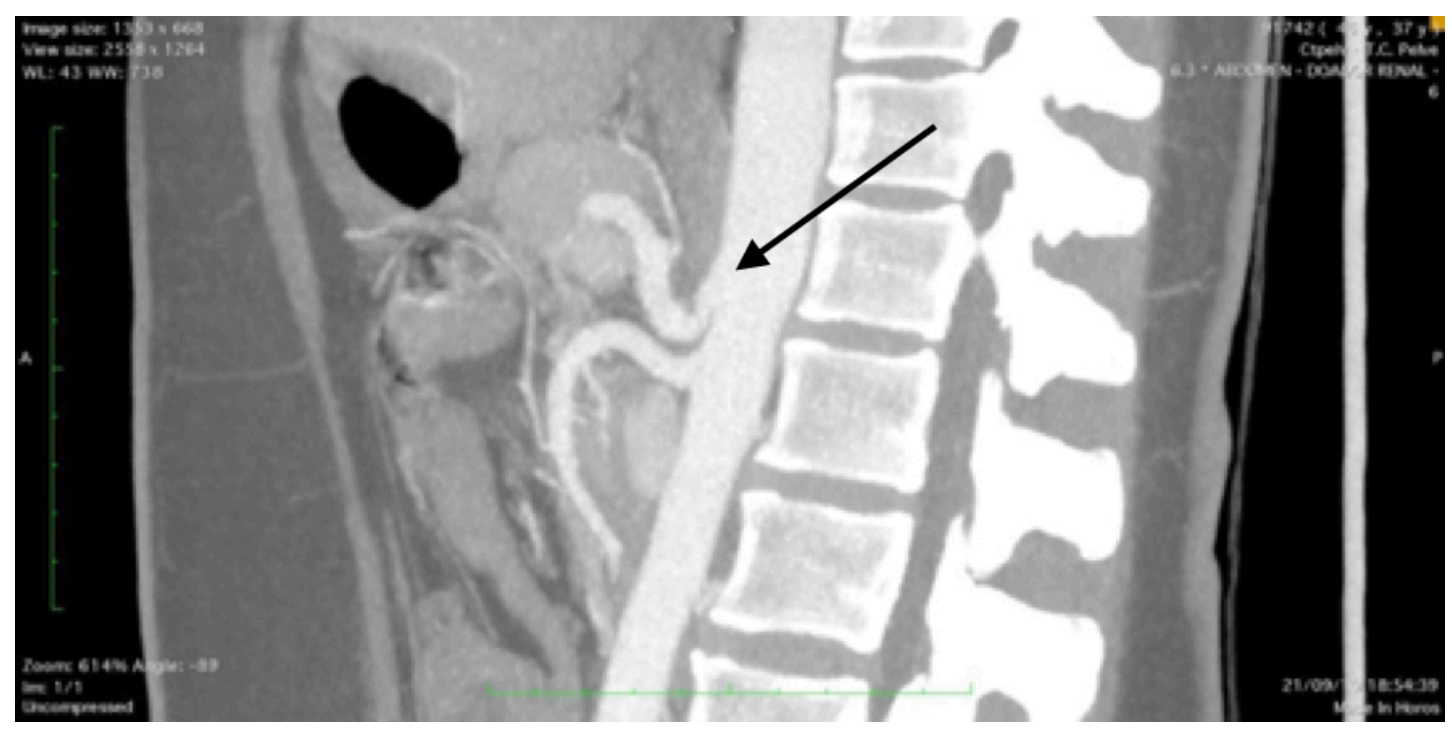

Figura 10 - Aspecto em "gancho" sem estenose associada

Frente à observação de que o aspecto de gancho é a conformação anatômica normal do tronco celíaco, não deve ser considerado um sinal radiológico de maior importância em indivíduos assintomáticos, sofrendo ainda influência de aspectos antropométricos.

Os relatos publicados de compressão do tronco celíaco em pacientes com ou sem sintomas, utilizam-se de variados critérios para o diagnóstico dessa condição, não havendo uniformidade na descrição. O sinal de gancho 
é comumente utilizado como indicativo de compressão extrínseca nas estenoses de tronco celíaco, distinguindo-as de estenoses provocadas pela doença aterosclerótica. Frequentemente, estenoses $>50 \%$ são consideradas, associadas a outros aspectos de imagem. A projeção sagital em tomografias computadorizadas, e as aquisições arteriográficas em projeção lateral são as que oferecem melhor visualização da origem e trajeto proximal do tronco celíaco. A estenose habitualmente ocorre de modo focal, na porção proximal da artéria, de alguns milímetros a centímetros de sua origem, preservando o óstio da mesma. Apresenta-se como estenose de aspecto excêntrico, ou assimétrico, predominante na porção superior da artéria, muitas vezes formando aspecto de indentação ou incisura. A incisura na parede superior da artéria parece ser o sinal mais indicativo de compressão extrínseca pelo $\mathrm{LAM}^{45}$. Dilatação pós-estenótica pode ser observada em lesões com maior grau de estenose. O tronco sofre desvio caudal em sua porção inicial, por efeito de deslocamento pelo LAM, assumindo trajeto quase paralelo à aorta e aproximando-se da parede anterior da aorta e da artéria mesentérica superior. Por vezes depressão sobre a parede anterior da aorta com visualização direta do LAM é observada. O LAM pode apresentar-se espessado e de fácil visualização tanto em projeção sagital como em cortes axiais na tomografia computadorizada $^{60}$. A presença de colaterais desenvolvidas na arcada pancreaticoduodenal, visualizadas em projeções anteroposteriores na arteriografia, ou cortes axiais na tomografia, tornam mandatória a aquisição de imagens em projeção lateral para identificação de lesões nas origens dos 
troncos viscerais. Da mesma forma, o achado de aneurismas da arcada pancreaticoduodenal também pode ser indicativo da presença de lesões estenosantes/oclusivas em tronco celíaco ou $\mathrm{AMS}^{61,62}$. Na presente casuística não foram observados aneurismas da arcada. A obtenção de gradientes pressóricos nas estenoses e a observação de padrões de fluxo também são citados, com opacificação retrógrada dos ramos celíacos através da arcada pacreaticoduodenal e gastroduodenal ao se realizar cateterização seletiva da AMS nas arteriografias ${ }^{38}$.

O fenômeno de compressão sofre influência dos movimentos respiratórios, com sua acentuação durante a expiração. Em arteriografias de projeção lateral realizadas em expiração e inspiração em pacientes com sopros abdominais ou queixas abdominais não explicadas, Reuter ${ }^{32}$ relatou alterações na conformação do tronco celíaco, com ascensão da artéria durante a expiração. A ocorrência de indentação no aspecto superior da artéria foi notada em alguns pacientes durante a expiração, e estenoses notadas durante a inspiração se acentuaram ou progrediram para obliteração total do vaso durante aquisições em expiração. Existe movimentação cranial dos órgãos abdominais, de modo que correspondente ascensão das artérias viscerais e ramos durante a expiração podem aproximar o tronco celíaco a um LAM localmente relacionado e relativamente fixo, levando à formação de um pinçamento ou acentuação de uma estenose prévia. Mais recentemente, estudo observando as variações geométricas dos vasos viscerais durante movimentos respiratórios, utilizando-se de Angiorressonância (AngioRM), observou que os vasos 
apresentam translação superior e posterior, acompanhada de alterações de suas curvaturas e angulações. O tronco celíaco é o vaso que apresenta maior deformação durante a expiração, com encurtamento e dobra devido à movimentação do diafragma e restrição pelo ligamento arqueado mediano ${ }^{63}$.

A prevalência de compressão encontrada na presente casuística poderia não representar o total de casos de compressão, em virtude dos exames tomográficos realizados em fase inspiratória, segundo o protocolo habitual da instituição; fazendo com que o efeito máximo da compressão pelo LAM, acentuado em fase expiratória não seja observado. Seria possível ainda, que o sinal do gancho com acentuada angulação do trajeto do tronco celíaco, pouco notado nos casos com estenose do presente estudo, pudesse ser observado se as imagens tomográficas fossem adquiridas em fase expiratória. Levin e Baltaxe ${ }^{7}$, em estudo arteriográfico de pacientes assintomáticos, com aquisições realizadas em fase expiratória encontraram $24 \%$ de estenoses $>50 \%$ e aspecto em $\cup$ (gancho). Ainda que a presente série possa ter subestimado a ocorrência de gancho devido as tomografias serem realizadas em inspiração, a alta frequência deste sinal em fase expiratória verificada no estudo supracitado, reduz sua importância enquanto indicativo de condição anormal. Adicionalmente, autores sugerem que somente as compressões que se mantém em fase inspiratória devem ser objeto de atenção, indicando uma estenose fixa. Estenoses que se apresentam de forma intermitente durante movimentos expiratórios dificilmente poderiam justificar isquemia visceral significativa e o achado delas em exames realizados em expiração, pode constituir falso positivo. 
Estudo de angioRM relatou incidência de $57 \%$ de estenoses de leves a severas (> 20\% a > 80\%) em aquisições durante expiração, com estas apresentando redução do grau de estenose em aquisições em fase inspiratória em sua maioria, 73\%. A baixa incidência de outros sinais como dilatação pós-estenótica ou circulação colateral desenvolvida, sugerem que o achado destas estenoses em fase expiratória podem mesmo constituir falso positivo ${ }^{64}$. O achado de compressão isolada do TC em exames realizados em fase expiratória pode não ter significância clínica, com autores sugerindo a realização dos exames de imagem nas duas fases, observandose a variação dinâmica da compressão e correlação com sintomatologia, além de complementação com outros exames complementares, como a ultrassonografia Doppler, que revela dados funcionais além dos anatômicos ${ }^{46}$.

Considerando que a maior parte dos protocolos de tomografia é realizada em fase inspiratória, o achado de compressão em pacientes com queixas não relacionadas ou assintomáticos, ainda que possa apresentar uma estimativa subestimada do fenômeno, parece representar as condições reais da prática clínica. Não se justifica a realização de exames adicionais em pacientes assintomáticos, baseado somente na observação isolada de fenômeno de compressão ou aspecto do tronco celíaco. Melhores critérios devem ser estabelecidos para a identificação de compressão do TC pelo LAM. Além disso, em pacientes com sintomas abdominais, recomenda-se cautela ao correlacionar sinais de compressão e sintomatologia, em virtude da fisiopatologia ainda não completamente elucidada da síndrome. 
Uma última limitação relacionada ao caráter retrospectivo no presente estudo se refere à confiabilidade acerca dos indivíduos da amostra serem de fato assintomáticos quanto às queixas abdominais, uma vez que o questionamento nos protocolos de doação renal é habitualmente direcionado a condições específicas que comprometeriam a evolução da função renal do doador, podendo subnotificar outras queixas não relacionadas, como por exemplo do trato gastrointestinal. No entanto, a medida de dados antropométricos faz parte da rotina de avaliação repetida destes pacientes, e a ocorrência de perda ponderal significativa seria prontamente reconhecida. Dor abdominal pós-prandial associada à perda ponderal pode não ter sido submetida à prospecção ativa, mas trata-se de queixa de significância clínica, a ser relatada espontaneamente pelos doadores. Em transplantes intervivos frequentemente doadores compatíveis são parentes próximos e o desejo de doação pode resultar em não relato intencional de sintomas pelos candidatos com o intuito de não comprometer o processo de doação. Por este motivo, os doadores são também avaliados psicologicamente quanto às motivações do ato de doação, a fim de excluir coerção externa ou emocional. Além disso os programas de doação intervivos são realizados com extremo cuidado, priorizando a saúde e bem-estar dos doadores em relação ao benefício esperado para o receptor, não sendo portanto, aceitáveis índices de complicação ou riscos elevados para o doador ${ }^{65,66}$. 
6 ConClusões 
a) A conformação de trajeto mais frequente do tronco celíaco em indivíduos saudáveis e assintomáticos, verificada à angiotomografia em projeção sagital, consiste em angulação caudal após sua origem, seguida de desvio cranial antes de sua primeira ramificação. A origem do tronco celíaco apresenta relação de proximidade com o ligamento arqueado mediano, sendo coberta total ou parcialmente pelo mesmo na maioria dos indivíduos.

b) Aspectos antropométricos como o peso corporal e índice de massa corpórea têm relação com a conformação do tronco celíaco em seu trajeto proximal, determinando variações nas angulações do tronco.

c) A prevalência de estenose do tronco celíaco atribuída a compressão pelo ligamento arqueado mediano, na população de indivíduos assintomáticos e saudáveis, observada em exame de angiotomografia, é de $3,4 \%$, compatível com os dados de literatura.

d) O sinal do gancho, descrito na literatura como típico da compressão extrínseca do TC, ocorre na minoria dos casos de estenose encontrados (dois entre 11); e também é observado em doadores sem estenose. 
7 AnEXo 


\section{Anexo A - Parecer do Comitê de Ética em Pesquisa}

HOSPITAL DAS CLINICAS DA
FACULDADE DE MEDICINA DA Platororma
USP - HCFMUSP

\section{PARECER CONSUBSTANCIADO DO CEP}

\section{DADOS DO PROJETO DE PESQUISA}

Título da Pesquisa: Avaliação quantitativa do sinal do gancho na origem do tronco celíaco em pacientes assintomáticos

Pesquisador: PEDRO PUECH-LEÃO

Área Temática:

Versão: 1

CAAE: 36389214.0 .0000 .0068

Instituição Proponente: Hospital das Clínicas da Faculdade de Medicina da USP

Patrocinador Principal: Financiamento Próprio

\section{DADOS DO PARECER}

Número do Parecer: 816.000

Data da Relatoria: 01/10/2014

\section{Apresentação do Projeto:}

Trata-se de um estudo clínico transversal, observacional, não controlado, baseado em análise de exames de imagem para determinação de parâmetros anatômicos normais. Serão revistas as imagens de angiotomografia de 200 doadores de rim registrados no Serviço de Transplante Renal do HCFMUSP. Este é um estudo anatômico. Os pacientes incluídos no estudo são considerados, por premissa, como normais.

Objetivo da Pesquisa:

O objetivo deste estudo é conhecer o grau de angulação do tronco celíaco, na sua origem, em pacientes assintomáticos submetidos à angiotomografia.

Avaliação dos Riscos e Benefícios:

Benefícios evidentes no progresso do conhecimento da anatomia normal dos vasos do tronco celíaco na população brasileira. Não há riscos relevantes para os sujeitos da pesquisa.

Comentários e Considerações sobre a Pesquisa:

Projeto adequado. Tempo proposto de 6 meses adequado.

Considerações sobre os Termos de apresentação obrigatória:

Solicitada dispensa de TCLE. Considero dispensa adequada.

Endereço:
Bairro:




\section{HOSPITAL DAS CLINICAS DA
FACULDADE DE MEDICINA DA Platoforma
USP - HCFMUSP}

Continuaçăo do Parecer: 816.000

\section{Recomendações:}

Aprovação

Conclusões ou Pendências e Lista de Inadequações:

Aprovação

Situação do Parecer:

Aprovado

Necessita Apreciação da CONEP:

Não

Considerações Finais a critério do CEP:

Em conformidade com a Resolução CNS n $466 / 12$ - cabe ao pesquisador: a) desenvolver o projeto conforme delineado; b) elaborar e apresentar relatórios parciais e final; c)apresentar dados solicitados pelo CEP, a qualquer momento; d) manter em arquivo sob sua guarda, por 5 anos da pesquisa, contendo fichas individuais e todos os demais documentos recomendados pelo CEP; e) encaminhar os resultados para publicação, com os devidos créditos aos pesquisadores associados e ao pessoal técnico participante do projeto; f) justificar perante ao CEP interrupção do projeto ou a não publicação dos resultados.

SAO PAULO, 02 de Outubro de 2014

Assinado por:

ALFREDO JOSE MANSUR

(Coordenador)

Endereço: Rua Ovídio Pires de Campos, $2255^{\circ}$ andar

Bairro: Cerqueira Cesar
UF: SP

Telefone: (11)2661-7585 Fax: (11)2661-7585

E-mail: cappesq.adm@hc.fm.usp.br 


\section{REFERÊNCIAS}


1. Harjola PT. A rare obstruction of the coeliac artery. Report of a case. Ann Chir Gynaecol Fenn. 1963;52:547-50.

2. Lipshutz B. A composite study of the coeliac axis artery. Ann Surg. 1917;65(2):159-69.

3. Dunbar JD, Molnar W, Beman FF, Marable SA. Compression of the celiac trunk and abdominal angina. Am $J$ Roentgenol Radium Ther Nucl Med. 1965;95(3):731-44.

4. Marable SA, Kaplan MF, Beman FM, Molnar W. Celiac compression syndrome. Am J Surg. 1968;115(1):97-102.

5. Marable SA, Molnar W, Beman FM. Abdominal pain secondary to celiac axis compression. Am J Surg. 1966;111(4):493-5.

6. Harjola PT, Lahtiharju A. Celiac axis syndrome. Abdominal angina caused by external compression of the celiac artery. Am J Surg. $1968 ; 115(6): 864-9$.

7. Levin DC, Baltaxe HA. High Incidence of Celiac Axis Narrowing in Asymptomatic Individuals. Am J Roentgenol. 1972;116(2):426-9. 
8. Szilagyi DE, Rian RL, Elliott JP, Smith RF. The celiac artery compression syndrome: does it exist? Surgery. 1972;72(6):849-63.

9. Hagspiel KD, Flors L, Hanley M, Norton PT. Computed tomography angiography and magnetic resonance angiography imaging of the mesenteric vasculature. Tech Vasc Interv Radiol. 2015;18(1):2-13.

10. McCarthy E, Little M, Briggs J, Sutcliffe J, Tapping CR, Patel R, Bratby MJ, Uberoi R. Radiology and mesenteric ischaemia. Clin Radiol. 2015;70(7):698-705.

11. Khosa F, Krinsky G, Macari M, Yucel EK, Berland LL. Managing incidental findings on abdominal and pelvic CT and MRI, part 2: White paper of the ACR Incidental Findings Committee II on vascular findings. J Am Coll Radiol. 2013;10(10):789-94.

12. Venieratos D, Panagouli E, Lolis E, Tsaraklis A, Skandalakis P. A morphometric study of the celiac trunk and review of the literature. Clin Anat. 2013;26(6):741-50

13. George R. Topography of the unpaired visceral branches of the abdominal aorta. J Anat. 1935;69(Pt 2):196-205.

14. Lin PH, Chaikof EL. Embryology, anatomy, and surgical exposure of the great abdominal vessels. Surg Clin North Am. 2000;80(1):417-33. 
15. White RD, Weir-mccall JR, Sullivan CM, Mustafa SAR, Yeap PM, Zealley IA. The celiac axis revisited: anatomic variants, pathologic features, and implications for modern endovascular management. RadioGraphics. 2015;35(1):879-98.

16. Panagouli E, Venieratos D, Lolis E, Skandalakis $P$. Variations in the anatomy of the celiac trunk: A systematic review and clinical implications. Ann Anat. 2013;195(6):501-11.

17. Hafezji HM, Gupta DS. A study of morphometric variations of celiac trunk using computed tomographic angiography. Indian J Clin Anat Physiol. 2016;3(1):86.

18. Lindner $\mathrm{HH}$, Kemprud E. A clinicoanatomical study of the arcuate ligament of the diaphragm. Arch Surg. 1971;103(5):600-5.

19. Paz Z, Rak Y, Rosen A. Anatomical basis for celiac trunk and superior mesenteric artery entrapment. Clin Anat. 1991;4(4):256-64.

20. Katz-Summercorn A, Bridger J. A cadaveric study of the anatomical variation of the origins of the celiac trunk and the superior mesenteric artery: A role in median arcuate ligament syndrome? Clin Anat. 2013;26(8):971-4.

21. Petrella S, Rodriguez CF de S, Sgrott EA, Fernandes GJM, Marques SR, Prates JC. Relationship of the celiac trunk with median arcuate ligament of the diaphragm. Int J Morphol. 2006;24(2):263-74. 
22. Loukas M, Pinyard J, Vaid S, Kinsella C, Tariq A, Tubbs RS. Clinical anatomy of celiac artery compression syndrome: a review. Clin Anat. $2007 ; 20(6): 612-7$.

23. Jonsson K, Wattsgård C, Genell S. Malignant Occlusion of the Coeliac Axis. Acta radiol. 1982;23(2):123-5.

24. Bron KM, Redman HC. Splanchnic artery stenosis and occlusion. Radiology. 1969;92(2):323-8.

25. Colapinto RF, McLoughlin MJ, Weisbrod GL. The routine lateral aortogram and the celiac compression syndrome. Radiology. 1972;103(3):557-63.

26. Yamamoto $M$, Itamoto $T$, Oshita A, Matsugu Y. Celiac axis stenosis due to median arcuate ligament compression in a patient who underwent pancreatoduodenectomy; Intraoperative assessment of hepatic arterial flow using Doppler ultrasonography: A case report. $J$ Med Case Rep. 2018;12(1):1-5.

27. Jurim O, Shaked A, Kiai K, Millis JM, Colquhoun SD, Busuttil RW. Celiac compression syndrome and liver transplantation. Ann Surg. $1993 ; 218(1): 10-2$

28. Ikeda O, Tamura Y, Nakasone Y, Yamashita Y. Celiac artery stenosis/occlusion treated by interventional radiology. Eur $J$ Radiol. 2009;71(2):369-77. 
29. Armstrong MB, Stadtlander KS, Grove MK. Pancreaticoduodenal artery aneurysm associated with median arcuate ligament syndrome. Ann Vasc Surg. 2014;28(3):741.e1-741.e5.

30. Brocker JA, Maher JL, Smith RW. True pancreaticoduodenal aneurysms with celiac stenosis or occlusion. Am $J$ Surg. 2012;204(5):762-8.

31. Brandt LJ, Boley SJ. Celiac axis compression syndrome - A critical review. Am J Dig Dis. 1978;23(7):633-40.

32. Reuter SR. Accentuation of celiac compression by the median arcuate ligament of the diaphragm during deep expiration. Radiology. $1971 ; 98(3): 561-4$.

33. Edwards AJ, Hamilton JD, Nichol WD, Taylor GW, Dawson AM. Experience with coeliac axis compression syndrome. $\mathrm{Br}$ Med $\mathrm{J}$. 1970;1(5692):342-5.

34. Julius $\mathrm{S}$, Stewart $\mathrm{BH}$. Diagnostic significance of abdominal murmurs. $N$ Engl J Med. 1967;276(21):1175-8.

35. McLoughlin MJ, Colapinto RF, Hobbs BB. Abdominal bruits clinical and angiographic correlation. JAMA. 1975;232(12):1238-42.

36. Drapanas T, Bron KM. Stenosis of the celiac artery. Ann Surg. 1966;164(6):1085-8. 
37. Cornell SH. Severe stenosis of the celiac artery. Analysis of patients with and without symptoms. Radiology. 1971;99(2):311-6.

38. Reuter SR, Olin T. Stenosis of the celiac artery. Radiology. 1965;85(4):616-27.

39. Petrella S, Prates JC. A review on the celiac trunk compression syndrome: some anatomic clinical-surgical aspects. Int $J$ Morphol. 2008;26(2):293-304.

40. Gruber H, Loizides A, Peer S, Gruber I. Ultrasound of the median arcuate ligament syndrome: a new approach to diagnosis. Med Ultrason. 2012;14(1):5-9.

41. Zwolak RM, Moneta GL, Lee RW, Yeager RA, Taylor LM. Mesenteric duplex scanning: A blinded prospective study. J Vasc Surg. 2002;17(1):79-86.

42. Youssef AT. Evaluation of asymptomatic patients with median arcuate ligament syndrome (Mals) Using color duplex ultrasound and computer tomographic (Ct) angiography. Am $J$ Cardiovasc Dis Res. 2013;1(10):7-11.

43. Fong JKK, Poh ACC, Tan AGS, Taneja R. Imaging findings and clinical features of abdominal vascular compression syndromes. $A m \mathrm{~J}$ Roentgenol. 2014;203(1):29-36. 
44. Eliahou R, Sosna J, Bloom Al. Between a rock and a hard place: clinical and imaging features of vascular compression syndromes. RadioGraphics. 2012;32(1):E33-49.

45. Horton KM, Talamini MA, Fishman EK. Median arcuate ligament syndrome: evaluation with CT angiography. Radiographics. 2005;25(5):1177-82.

46. Lamba R, Tanner DT, Sekhon S, McGahan JP, Corwin MT, Lall CG. Multidetector CT of vascular compression syndromes in the abdomen and pelvis. RadioGraphics. 2014;34(1):93-115.

47. Ozbülbül NI. CT angiography of the celiac trunk: anatomy, variants and pathologic findings. Diagn Interv Radiol. 2011 Jun;17(2):150-7.

48. Baskan O, Kaya E, Gungoren FZ, Erol C. Compression of the celiac artery by the median arcuate ligament: multidetector computed tomography findings and characteristics. Can Assoc Radiol J. $2015 ; 66(3): 272-6$.

49. Enterline J, Moser K, Hulse M, Haluck R, Moore M. Single injection, inspiratory/expiratory high-pitch dual-source CT angiography for median arcuate ligament syndrome: Novel technique for a classic diagnosis. J Cardiovasc Comput Tomogr. 2012;6(5):357-9.

50. Hagspiel KD, Leung DA, Angle JF, Spinosa DJ, Pao DG, de Lange EE, Butty S, Matsumoto $\mathrm{AH}$. MR angiography of the mesenteric vasculature. Radiol Clin North Am. 2002;40(4):867-86. 
51. van Dijk LJ, van Petersen AS, Moelker A. Vascular imaging of the mesenteric vasculature. Best Pract Res Clin Gastroenterol. $2017 ; 31(1): 3-14$

52. Bech FR. Celiac artery compression syndromes. Surg Clin North Am. 1997; 77: 409-24.

53. Gaebel G, Hinterseher I, Saeger HD, Bergert H. Compression of the left renal artery and celiac trunk by diaphragmatic crura. $J$ Vasc Surg. 2009;50(4):910-4.

54. Lee JJ, Mills JL. Chronic mesenteric ischemia from diaphragmatic compression of the celiac and superior mesenteric arteries. Ann Vasc Surg. 2016;30:311.e5-311.e8.

55. Doyle AJ, Chandra A. Chronic mesenteric ischemia in a 26-year-old man: Multivessel median arcuate ligament compression syndrome. Ann Vasc Surg. 2012;26(1):108.e5-108.e9.

56. Gümüş $H$, Gümüş $M$, Tekbaş $G$, Önder $H$, Ekici $F$, Çetinçakmak $M G$, Bilici A. Clinical and multidetector computed tomography findings of patients with median arcuate ligament syndrome. Clin Imaging. 2012 Sep-Oct;36(5):522-5.

57. Soman S, Sudhakar SV, Keshava SN. Celiac axis compression by median arcuate ligament on computed tomography among asymptomatic persons. Indian J Gastroenterol. 2010;29(3):121-3. 
58. Park CM, Chung JW, Kim HB, Shin SJ, Park JH. Celiac Axis Stenosis: Incidence and Etiologies in Asymptomatic Individuals. Korean J Radiol. $2001 ; 2(1): 8-13$

59. Asbeutah AM, Bakir YY, Swamy N, Absuetah AAA, Abu-Asi MA, Sharma P. Subject body mass index affects doppler waveform in celiac artery by duplex ultrasound. Open Cardiovasc Med J. 2013;7(1):40-5.

60. Ilica AT, Kocaoglu M, Bilici A, Ors F, Bukte Y, Senol A, Ucoz T, Somuncu I. Median arcuate ligament syndrome: multidetector computed tomography findings. $J$ Comput Assist Tomogr. $2007 ; 31(5): 728-31$.

61. Vandy FC, Sell KA, Eliason JL, Coleman DM, Rectenwald JE, Stanley JC. Pancreaticoduodenal and gastroduodenal artery aneurysms associated with celiac artery occlusive disease. Ann Vasc Surg. $2017 ; 41: 32-40$.

62. Degheili JA, El Chediak A, Dergham MYR, Al-Kutoubi A, Hallal AH. Pancreaticoduodenal artery aneurysm associated with celiac trunk stenosis: case illustration and literature review. Case Rep Radiol. 2017;2017:1-7.

63. Suh GY, Choi G, Herfkens RJ, Dalman RL, Cheng CP. Threedimensional modeling analysis of visceral arteries and kidneys during respiration. Ann Vasc Surg. 2016;34(April):250-60. 
64. Lee V, Morgan J, Tan A. Vascular and interventional radiology-celiac artery compression by the median arcuate ligament: a pitfall of endexpiratory MR Imaging. Radiology. 2003;(5):437-42.

65. Barlow AD, Ghoneima AS. Kidney transplantation. Surg (United Kingdom). 2020;38(7):398-404.

66. Tong A, Chapman JR, Wong G, Kanellis J, McCarthy G, Craig JC. The motivations and experiences of living kidney donors: A thematic synthesis. Am J Kidney Dis. 2012;60(1):15-26. 
APÊNDICE 


\section{Apêndice A - Artigo publicado}

NIH) National Library of Medicine

PublMed.gov

Observational Study ～> J Vasc Surg. 2018 Dec;68(6):1782-1787. doi: 10.1016/j.jvs.2018.04.044 Epub 2018 Jun 15.

\section{Prevalence of signs of celiac axis compression by the median arcuate ligament on computed tomography angiography in asymptomatic patients}

Alexandre Petnys ${ }^{1}$, Pedro Puech-Leão ${ }^{2}$, Antonio Eduardo Zerati ${ }^{2}$, Raphael Mendes Ritti-Dias ${ }^{2}$, William Carlos Nahas ${ }^{3}$, Elias David Neto ${ }^{3}$, Nelson De Luccia ${ }^{2}$

Affiliations + expand

PMID: 29914831 DOI: 10.1016/j.jvs.2018.04.044

Free article

\section{Abstract}

Objective: The increasing use of computed tomography $(\mathrm{CT})$ angiography has led to more frequent diagnoses of celiac artery compression (CAC) by the median arcuate ligament (MAL). The signs of CAC by the MAL have been described as stenosis and a hook or $J$ appearance on sagittal views. The importance of the "hook signal," however, has not been documented by studies of the normal anatomy of the celiac axis.

Methods: CT angiography images of 344 completely asymptomatic, live kidney donors (without history of chronic abdominal pain or weight loss) were reviewed. The angle of emergence (AE) of the celiac axis from the aorta and the angle of upward or downward shifting of the celiac axis before its first branch (fold angle [FA]) were measured. Weight, height, and body mass index were obtained from our electronic database, and correlations with the angles measured were tested. The occurrence of stenosis $>50 \%$ at the origins of the celiac axis was also determined in the sample.

Results: Measurements were possible in 321 cases. The celiac axis was found to leave the aorta at an angle of $<90$ degrees in all patients (AE range, $7-83$ degrees) and $<45$ degrees in 292 (90\%) patients. The FA ranged from 66 to 208 degrees. Before the first branch, the celiac trunk shifted upward in 306 (95\%) patients, remained straight in just one of them, and shifted downward in $14(4 \%)$. The AE was positively correlated with weight in women. The FA was negatively correlated with weight in men and women. Body mass index was positively correlated with $\mathrm{AE}$ and negatively correlated with FA in both men and women. In 11 cases (3.4\%), stenosis $>50 \%$ was found at the origin of the celiac axis. In only two patients, the celiac axis had an upward slope after the stenosis, which could be interpreted as a hook shape.

Conclusions: The normal anatomy of the celiac axis, when seen on CT angiography images, demonstrates that it exits the aorta downward and then shifts upward. This hook or J shape should not be interpreted as resulting from external compression. CAC by the MAL occurs in $3.42 \%$ of the normal asymptomatic population; a hook or $J$ shape is not visible in most cases in that subgroup.

Keywords: Asymptomatic patients; CT angiography; Celiac artery/axis compression; Median arcuate ligament

Copyright $\odot 2018$ Society for Vascular Surgery. Published by Elsevier Inc. All rights reserved.
FULL TEXT LINKS

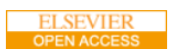

ACTIONS

\section{G6 Cite}

¿ Favorites

SHARE

$0 \oplus \odot$

PAGE NAVIGATION

$<$ Title \& authors

Abstract

Comment in

Similar articles

Cited by

Publication types

MeSH terms

Related information

LinkOut - more

resources 